\title{
Literatura Normativa Pragmática e a Produção de Conhecimento Normativo nos Impérios Ibéricos do Início da Idade Moderna (Séculos XVI-XVII)*
}

\author{
Pragmatic Normative Literature and the Production of Normative Knowledge in the Early \\ Modern Iberian Empires (16 $6^{\text {th }}-17^{\text {th }}$ Centuries)
}

Thomas Duve**

\section{REFERÊNCIA}

DUVE, Thomas. Literatura Normativa Pragmática e a Produção de Conhecimento Normativo nos Impérios Ibéricos do Início da Idade Moderna (Séculos XVI-XVII). Revista da Faculdade de Direito da UFRGS, Porto Alegre, n. 42, p. 3-44, abr. 2020. DOI: < https://doi.org/10.22456/0104-6594.102154>.

\section{RESUMO}

Este capítulo introdutório tem por objetivo mostrar o papel da 'literatura normativa pragmática' no regime histórico de produção de conhecimento nos impérios ibéricos do início da Idade Moderna (séculos XVI-XVII) e definir esse gênero literário em vista de sua função. Ele começa com uma tentativa de apresentar a história do direito dos impérios ibéricos como parte de uma tradição jurídica que pode ser compreendida como um enorme processo diacrônico de intertextualidade, uma longa história de atos reiterativos de tradução de informação normativa em conhecimento normativo. Ele destaca a razão pela qual o conhecimento normativo produzido por atores religiosos foi de grande significância dentro da economia do conhecimento dos impérios ibéricos nos séculos XVI e XVII e como teologia prática, práticas normativas e literatura pragmática estavam entrelaçadas. Dessa reconstrução de certas características fundamentais, é possível sugerir a definição de 'literatura normativa pragmática', resumir o atual estado das pesquisas sobre as formas de comunicação que compuseram o gênero e concluir com alguns comentários sobre por que razão a literatura pragmática pode ter sido de especial significado para governar um império.

\section{PALAVRAS-CHAVE}

História do direito. Teologia moral. História do Conhecimento. América Latina Colonial. História do livro jurídico.

\footnotetext{
* Sobre a publicação: A publicação original em língua inglesa teve duas versões, ambas utilizadas aqui. Primeiramente, o texto foi publicado na condição de "working paper": DUVE, Thomas. Pragmatic Normative Literature and the Production of Normative Knowledge in the Early Modern Iberian Empires in the $16^{\text {th }}-17^{\text {th }}$ Centuries. Max Planck Institute for European Legal History - Research Paper Series, n. 2019-19. Disponível em: https://papers.ssrn.com/sol3/papers.cfm?abstract_id=3447223. Após, como capítulo de livro: DUVE, Thomas. Pragmatic Normative Literature and the Production of Normative Knowledge in the Early Modern Iberian Empires (16 $6^{\text {th }}-17^{\text {th }}$ Centuries). In: DUVE, Thomas; DANWERTH, Otto (ed.). Knowledge of the Pragmatici: Legal and Moral Theological Literature and the Formation of Early Modern Ibero-America. Leiden; Boston: Brill-Nijhoff, 2020. p. 01-39. Tradução para a língua portuguesa por Gregório Schroder Sliwka (Mestrando em Direito no PPGDir-UFRGS). Revisão por Alfredo de J. Flores (Prof. Permanente PPGDirUFRGS). Os tradutores agradecem o apoio na edição do texto da parte de Guilherme Tumelero Macedo (graduando em Direito-UFRGS). A base da tradução partiu do primeiro texto, o que foi autorizado pelo próprio autor, Thomas Duve. A posterior publicação em capítulo pela Editora Brill (DOI:

https://doi.org/10.1163/9789004425736_002) somente nos serviu de baliza para a atualização do texto. Quanto às citações ao longo do texto, optou-se por manter o sistema adotado pelo autor.

** Sobre o autor: Professor Doutor de História do Direito em Perspectiva Comparada na Goethe-Universität Frankfurt am Main e membro científico da Sociedade Max-Planck desde 2009, ocupando desde 2010 o cargo de diretor no Max Planck Institute for European Legal History.

Agradecimentos do autor: Eu sou grato pelos comentários dos membros do grupo de pesquisa 'The Knowledge of the pragmatici', a Nicole Pasakarnis, Christian Pogies e Alexandra Woods pela ajuda na edição do texto e comentários e a Tamar Herzog por suas sugestões.
} 


\begin{abstract}
This introductory chapter aims to show the role of 'pragmatic normative literature' in the historical regime of knowledge production in the early modern Iberian Empires during the 16th and 17th centuries and to define this literary genre in the light of this function. It starts with an attempt to present the legal history of the Iberian empires as part of a legal tradition that can be understood as a huge diachronic process of intertextuality, a long history of reiterative acts of translating normative information into normative knowledge. It outlines why normative knowledge produced by religious actors was of overwhelming significance within the knowledge economy of the 16th-and 17th-century Iberian empires and how practical theology, normative practices and pragmatic literature were intertwined. From this reconstruction of certain fundamental characteristics, it is possible to suggest a definition of 'pragmatic normative literature', to summarize the current state of research on the media that comprised this genre and to conclude with some remarks on why pragmatic literature might have been of special significance for governing an empire.
\end{abstract}

\title{
KEYWORDS
}

Legal History. Moral Theology. History of Knowledge. Colonial Latin America. History of Legal Books.

\section{SUMÁRIO}

1. Introdução. 2. História do direito como um processo de intertextualidade diacrônica. 3. Traduções. 3.1. Da informação normativa ao conhecimento normativo. 3.2. Conhecimento normativo na prática. 4. Conhecimento normativo religioso e secular. 5. Teologia prática e literatura pragmática. 6. Literatura normativa pragmática: descrição e definição. 7. Entre o direito nos livros e o direito em ação. 8. Grandes impérios, pequenos livros? Referências. Dados da publicação. 


\section{INTRODUÇÃO}

Ordens normativas são uma construção social e cultural, produzida e transformada em um processo contínuo por uma multitude de atores. Elas são criadas, modificadas e estabilizadas pela produção, conservação, processamento, legitimação - e assim também pela deslegitimação e esquecimento - de informação normativa. Esse processo de contínua tradução de informação normativa em conhecimento normativo resulta em ordens normativas históricas que moldam seu formato através da informação normativa disponível, da configuração contingente de atores e actantes ${ }^{\mathrm{a}}$, das relações de poder entre eles, como também através das condições sociais, culturais e materiais peculiares a uma configuração histórica concreta.

Pesquisas em história do direito e em história geral têm cada vez mais nos provido de informações sobre vários desses elementos. Com isso, nós podemos ambicionar entender por que uma ordem normativa se tornou historicamente o que ela é; por que, por exemplo, alguns regimes de governo, diversidade, dependência etc., emergiram em um espaço mais ou menos específico e em um tempo mais ou menos específico. Ao reconstruir os elementos que constituem esses regimes históricos, como eles interagem e mudam, e entendendo suas transformações e entrelaçamentos no tempo se está no núcleo da pesquisa em história do direito.

Este livro ${ }^{\mathrm{b}}$, no entanto, não se ocupa de nenhum desses regimes históricos específicos ${ }^{1}$. Ele não reconstrói a história do trabalho forçado, da propriedade ou de outras instituições como formações históricas no mundo ibérico dos séculos XVI ou XVII. Ele foca em um aspecto diferente: compreender como a produção de conhecimento normativo no início da Idade Moderna no mundo ibero-americano colonial funcionou e qual papel um gênero literário, conceituado neste livro como "literatura normativa pragmática", desempenhou neste processo. Formulado em termos da história do conhecimento, o objeto deste livro é a reconstrução de um regime histórico de produção de conhecimento no campo da normatividade e a funcionalidade de um meio específico neste campo ${ }^{2}$.

a Nota de tradução: O termo original "actants" é próprio da Semiótica, denotando aqueles participantes ativos de narrativas.

b Nota de tradução: referindo-se ao livro coletivo já citado aqui em nota de rodapé.

10 termo "regime histórico" é entendido aqui como uma formação histórica mais ou menos estabilizada de práticas, regras, princípios e normas específicas em um certo campo de ação. Essa definição retoma o debate conceitual de Krasner (1983), que foi posteriormente desenvolvido em várias disciplinas científicas culturais e sociais. Ver, sobre isso, o levantamento de List (2007).

$2 \mathrm{O}$ 'regime histórico de produção de conhecimento no campo da normatividade' pode ser entendido como uma formação histórica mais ou menos estável de práticas, regras, princípios e normas específicas de produção de 
Devido à necessidade de reduzir a escala de observação e considerando a importância do conhecimento normativo do campo da religião nos mundos ibero-americanos dos séculos XVI e XVII, a maioria dos capítulos deste livro estuda a literatura pragmática relacionada com a teologia moral e o direito canônico e sua produção e uso por teólogos, missionários e autoridades da Igreja. Eles apresentam visões sobre o papel fundamental que atores do campo religioso tiveram no estabelecimento de algo como uma literacia ${ }^{c}$ normativa colonial, uma capacidade de manejar conhecimentos básicos das regras da vida social colonial ${ }^{3}$. Eles podem, assim, ajudar a entender como o conhecimento normativo atingiu uma audiência ampla e foi traduzido em interações cotidianas, uma questão fundamental de história do direito colonial que com frequência fica sem resposta, se focarmos apenas em ações e padrões de comportamento sem se perguntar pelo conhecimento subjacente. Nesse sentido, eles são, assim como todo o volume, uma contribuição para um projeto intelectual mais amplo que objetiva compreender a história do direito colonial ibérica enquanto parte de um processo histórico 'glocal' de produção de conhecimento, impulsionado por comunidades epistêmicas diferentes, flexíveis e sobrepostas e por comunidades de prática com suas próprias esferas de comunicação, com ênfase específica no conhecimento normativo produzido por atores do campo religioso ${ }^{4}$.

Os objetivos deste capítulo são introduzir algumas características básicas deste regime histórico de produção de conhecimento, mostrar como a história do direito poderia ser vista

conhecimento normativo. Essa definição retoma e especifica a definição de 'regimes de conhecimento', desenvolvida por Wehling (2007, p. 704). Ver também, em regimes de conhecimento, Böschen (2016). Em termos gerais, optamos pelo conceito de 'regimes históricos de conhecimento' e não por 'Wissenskulturen', discutido na academia alemã nos anos 1990 em razão da proximidade do debate sobre 'regimes de conhecimento' com o campo da história da epistemologia e da praxiologia [praxeology], desenvolvido principalmente na história da ciência. Para um levantamento do uso de 'Wissenskulturen', ver Zittel (2014). Em 'conhecimento jurídico', ver as inspiradoras observações de James Boyd White (2002, p. 1399), descrevendo o conhecimento jurídico "como uma atividade da mente, uma forma de fazer algo com as regras e casos e outros materiais do direito, uma atividade que é ela mesma irredutível a um conjunto de diretrizes ou a qualquer descrição fixa. É uma espécie de competência cultural, como aprender uma linguagem". Sobre as razões de nós preferirmos falar de conhecimento "normativo" e não de "conhecimento jurídico", ver, de uma perspectiva teórico-jurídica, Möllers (2015), e, de uma perspectiva histórico-jurídica, Duve (2017b).

c Nota de tradução: O termo original "literacy", que tem um sentido mais próprio na Linguística, tem tradução como "literacia" em Portugal, no sentido de formação desde práticas sociais de leitura, escrita e oralidade. O termo ainda tem pouco uso no Brasil, mas indica a ideia de formação, que se relaciona com o presente texto. 3 Ver, sobre este aspecto, as contribuições recentes em Owensby e Ross (2018).

4 Ver, para essa perspectiva, Duve $(2011,2015)$; ela também baseia o volume coletivo dedicado a Salamanca como um fenômeno da produção global de conhecimento, a ser publicado em 2020: Duve et al. (eds.) (no prelo). Como parte de uma tentativa de colocar a história do direito europeia em perspectiva global, ver como referência adicional Duve (2017a, 2018a). Da perspectiva da história do conhecimento, importantes contribuições foram desenvolvidas por Jürgen Renn, especialmente no volume Renn (2012). Sobre a relevância e potencial de interação entre história do direito global e história do conhecimento, ver Renn (2014). Sobre as premissas metodológicas subjacentes à ideia de "esferas de comunicação", próxima ao que se chama "comunidades de prática" e "comunidades epistêmicas", ver Hespanha (2018). 
como um processo de produção de conhecimento e sugerir uma definição de "literatura normativa pragmática" como um importante meio neste regime histórico específico ${ }^{5}$. Este, consequentemente, começa com uma tentativa de apresentar a história do direito dos impérios ibéricos como parte de uma tradição jurídica que pode ser entendida como um grande processo diacrônico de intertextualidade (2), uma longa história de atos reiterados de tradução de informação normativa em conhecimento normativo (3). Ele delineia por que o conhecimento normativo produzido por atores religiosos foi de enorme significância na economia do conhecimento dos impérios ibéricos nos séculos XVI e XVII e como a teologia prática, as práticas normativas e a literatura pragmática estavam entrelaçadas $(4,5)$. A partir desta reconstrução de certas características básicas, é possível sugerir a definição de "literatura normativa pragmática" (6), resumir o estado da arte das formas de comunicação incluída neste gênero na historiografia do direito, do direito canônico e da teologia moral (7) e concluir com alguns comentários sobre por que a literatura pragmática pode ter sido de especial significância para governar um império (8).

\section{HISTÓRIA DO DIREITO COMO UM PROCESSO DE INTERTEXTUALIDADE DIACRÔNICA}

A história do direito na Europa pode ser interpretada como um grande processo de tradução diacrônica de informação normativa e, portanto, também como uma história de processos recursivos de encerramento e diferenciação de corpos em conhecimento normativo. Embora inseparável da esfera secular, a Igreja, suas instituições e seu pessoal e as formas de comunicação produzidas por eles eram, talvez, os condutores mais importantes deste processo. Séculos de pesquisa foram dedicados à reconstrução desta história, frequentemente apresentada como a formação de uma distinta tradição jurídica ocidental. Enquanto esta história foi tradicionalmente escrita com um claro foco no redescobrimento do Direito Romano na Idade Média e vista como um processo histórico-cultural de cientifização, secularização e profissionalização que levou ao Estado moderno, importantes contribuições

\footnotetext{
5 Para uma introdução geral ao campo 'história do conhecimento', ver Burke (2015) com referências posteriores. Para uma boa introdução à discussão sobre a relação entre história da ciência e história do conhecimento, assim como aos conceitos de 'conhecimento', ver Renn (2015); Lorraine Daston reflete sobre riscos e oportunidades da abertura da história da ciência à história do conhecimento, que poderia se aplicar, mutatis mutandis, ao campo da história do direito (Daston, 2017). Uma boa introdução também em Müller-Wille et al. (2017).
} 
nas últimas três décadas enfatizaram o papel fundamental do direito canônico, dos atores da Igreja e da Religião nesta história ${ }^{6}$.

Sem ser capaz de adentrar muito nesta grande e complexa história, pode ser suficiente para os propósitos deste capítulo apontar que foi, pelo menos, a contínua atualização pela seleção e adição em uma rede epistêmica que garantiu a identidade e, simultaneamente, as dinâmicas e, portanto, a funcionalidade dessas ordens normativas no tempo.

Já nas culturas jurídica do início do Medievo, construídas em torno de uma pequena quantidade de textos escritos e produzidas em constelações complexas com a oralidade, a intertextualidade era tão forte que alguns destes 'textos vivos' foram chamados "monstros mutantes" ". Entretanto, com o passar do tempo, mais e mais conhecimento normativo novo foi produzido e conservado em escrita de modo que o corpo de normatividade acessível cresceu continuamente. Na altura do século XI, no máximo, teologia e direito tinham então começado a desenvolver uma atitude diferente em relação ao legado destes textos de autoridade. As pessoas sem dúvida ainda se sentiam obrigadas pelas decisões do passado, mas se aproximavam delas em maneiras que são comumente vistas como o começo da dogmática jurídica: novas estratégias intelectuais para lidar com as partes da tradição aparentemente contraditórias - por exemplo, utilizando a técnica da distinção -, foram acompanhadas pelo uso de novos formatos e novos gêneros literários, uma nova organização do conhecimento por uma ordem não-cronológica, novos mecanismos de busca, paratextos etc., todos tendo importantes efeitos na interpretação do conteúdo.

Em adição ao constante crescimento do conhecimento normativo existente graças ao estímulo ao longo do tempo e apesar das perdas e esquecimentos de normatividade, os textos cada vez mais complexos com suas diversas camadas históricas - e agora interpretações - se tornaram mais facilmente acessíveis. Já ao fim da Idade Média, os existentes bem como os

\footnotetext{
6 Considerando o vasto período coberto e o caráter introdutório deste capítulo, referências bibliográficas têm de ser limitadas, especialmente em questões de método e em referências específicas à literatura pragmática. Para um delineamento geral da História do Direito Europeu ou Ocidental e malgrado as limitações resultantes da perspectiva eurocêntrica assim como do foco nas tradições jurídicas eruditas e da necessidade de redução da complexidade, as magistrais narrativas de Wieacker (1996), Grossi (2010) e Berman (1983) provêm o leitor com uma boa introdução ao campo. Com atenção especial à dimensão religiosa e à prática de administração da justiça, ver Prodi (2000). Já Hespanha (2012) e Herzog (2018) apresentaram visões novas da História do Direito Europeia, incluindo a dimensão colonial. Para uma primeira orientação, ver também os diferentes capítulos em Pihlajamäki et al. (2018). Já para o assim chamado Derecho Indiano, a história do direito colonial da América espanhola, a melhor introdução sobre a sua racionalidade e suas práticas é Tau Anzoátegui (1992); para o império português, ver Hespanha $(2015,2019)$. Para uma visão comparativa da historiografia hispânica e portuguesa, ver Hespanha (2017). A combinação de tradução com uma perspectiva evolutiva apresentada aqui não é menos agradecida aos escritos de H. P. Glenn e sua conceitualização de 'tradição jurídica' - ver sobre isso mais extensivamente em Duve (2018).

7 Ver: Firey (2010).
} 
novos textos normativos (no assim chamado ius novum) foram copiados em crescentes números devido às novas formas de produção (como o sistema pecia) e à passagem geral "da memória ao registro escrito"8. Manuscritos foram usados nas várias recém-fundadas universidades e pelo crescente números de profissionais, guardados em livrarias e passados de geração em geração. Em outros termos, a massa de informação normativa que podia ser usada para produzir novo conhecimento normativo ficou ainda maior, as margens de flexibilidade cresceram e várias tentativas de lidar com essa avalanche de informação produziu novas formas de comunicação em que esta informação poderia ser guardada - e multiplicada.

Com o uso da impressão, esse processo de 'looping e feedback' de informação normativa ganhou ainda mais expressão, ao menos por que esta assim chamada revolução nas formas de comunicação coincidiu com outros importantes acontecimentos na Europa do fim do século XV e do século XVI - como a expansão europeia, reformas e a emergência do Estado pré-moderno. Tanto eruditos católicos quanto protestantes agora examinavam o conhecimento normativo proveniente da tradição, seja em teologia como em direito canônico, e preparavam sempre renovados trabalhos de fundação, bem como compêndios de sua visão de mundo, e suas confissões, também no campo do direito. Em parte devido a esta confessionalização, novas universidades foram fundadas em vários locais da Europa e o número de estudantes universitários cresceu em larga escala para suprir a crescente necessidade de pessoal nos enormes aparatos administrativos que surgiam. Pelo menos nas monarquias ibéricas, instituições de governo cresciam e novas práticas emergiram como resposta às dimensões imperiais; o mesmo se aplica à Cúria Romana e às ordens religiosas que se tornaram "players" globais.

As expansões europeias para outros continentes e suas múltiplas consequências como aumento das trocas, necessidade de governança imperial e atividades missionárias massivas, mas também a profissionalização da administração da justiça, demandaram compilações reprodutíveis do conhecimento normativo como a literatura confessional e catequética, bem como de informações básicas em direito (canônico). A missão também trouxe novos desafios intelectuais, incluindo questões sobre como lidar com povos indígenas e suas leis e crenças, que eram desconhecidas para o mundo católico e diferente das categorias estabelecidas de infideles. Essas questões motivaram diversos autores e instituições dos dois lados do Atlântico, e depois nas porções do império no Pacífico, a editar novos textos, valendo-se de e transformando a tradição literária existente tanto na Europa quanto nas Américas, como 


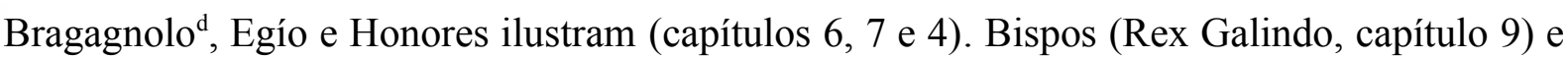
assembleias da Igreja, em particular o extraordinariamente importante Terceiro Concílio Provincial de Lima (1582/83) e do México (1585), viram como sua responsabilidade especial redigir textos normativos que eram relevantes às suas dioceses e orientados às necessidades práticas. Ao mesmo tempo, eles tinham de atender às importantes produções dogmática e legislativa elaboradas em Trento e seu ambiente intelectual. O Terceiro Concílio Provincial Mexicano, por exemplo, produzido não só cânones, mas também um manual para confessores, três catecismos e um rituale, um livro que provia toda informação necessária a um padre na sua atuação dos ritos litúrgicos (Moutin, capítulo 8). Esses textos pragmáticos frequentemente referiam-se à necessidade de integrar as reformas discutidas em Trento, muitas das quais continuaram e forma implementadas depois do encerramento do Concílio em 1563.

Esses exemplos chamam nossa atenção para a expansão das ordens normativas da Igreja Católica e, ao mesmo tempo, à necessidade de adaptar, definir e selecionar o conhecimento normativo relevante para áreas ou grupos particulares dentro do mundo católico em crescimento. Em termos mais abstratos: nós podemos observar que, com as quase contemporâneas expansão europeia e revolução das formas de comunicação, uma crescente variedade de comunidades epistêmicas produziu corpos de conhecimento normativo, valendose de textos existentes, modificando e interpretando-os, frequentemente com comunidades específicas de prática em mente. A rede epistêmica agora abrangia grandes territórios e a variedade de situações levava à crescente diferenciação. Assim, o assim chamado 'pluralismo jurídico', inerente ao direito europeu medieval e protomoderno, tornou-se ainda mais complexo: a tentativa de prover diversas comunidades de prática com as ferramentas adequadas às suas tarefas acelerou o contínuo processo de diferenciação entre as ordens normativas entrelaçadas, presentes no mundo católico. Por exemplo, membros de poderosas ordens religiosas, como dominicanos ou jesuítas, seguiram opiniões diferentes sobre problemas de grande importância prática, como usura e restituição. Na mesma linha, Igrejas provinciais, como aquelas do Peru e do México, começaram a desenvolver políticas jurídicas distintas, por exemplo, em relação à inclusão ou exclusão de populações indígenas e mestiças no clero. As circunstâncias específicas das partes americanas e asiáticas das monarquias levaram atores a desviar de soluções estabelecidas na Europa, sustentando que circunstâncias diferentes requeriam novas soluções a problemas velhos e que esses problemas necessitavam d Nota de tradução: Estes são autores de outros capítulos do livro "Knowledge of the Pragmatici", publicado pela Brill. 
de conhecimento específico que só poderia ser adquirido com a prática. Isso é o que, por exemplo, o primeiro bispo de Manila, o frei dominicano Domingo de Salazar que viveu por décadas no México antes de chegar às Filipinas, queria dizer quando escreveu ao imperador em 1582 que, conquanto tantos excelentes conselheiros de todas as disciplinas servissem à Corte, para decidir adequadamente sobre os assuntos das Índias não havia dúvida de que "era necessário ter estado lá, e não apenas por alguns anos"

Entretanto, mesmo com a diferenciação, as localizações e especificações que resultaram dessa globalização da Igreja e suas instituições e a tentativa de adaptar seu conhecimento normativo às exigências de cada local, não ocorreu o encerramento dos diferentes regimes jurídicos que surgiram. Pelo contrário, a necessidade de atualizar o corpo de conhecimento normativo e de responder a problemas concretos abriu estes regimes jurídicos ao conhecimento normativo vindo de campos, regiões e corpos regulatórios diferentes. A observação concomitante do que era feito em outras partes da policêntrica monarquia espanhola ou do esparso império português era prática frequente e, como consequência, quando uma solução clara inexistia em um lugar, era possível argumentar que a prática que era legitimada no Panamá poderia servir para Lima ou para o México e vice-versa. Além disso, a medida que os costumes eram considerados uma fonte do direito, uma lex non scripta - e esses costumes continuamente eram (re)criados e posteriormente reconhecidos -, a prática diária produzia novos conhecimentos normativos que poderiam eventualmente ser usados também em outros casos, enriquecendo o corpo de conhecimento normativo de que os atores poderiam ser servir. Acima de tudo, reis e papas, corpos regulatórios intermediários bem como autoridades locais constantemente produziam novas reales cédulas, provisiones, bulas, breves etc., frequentemente dirigidas a destinatários específicos, mas conhecidas e consideradas em outros locais. Para se ter uma ideia da produtividade desses corpos regulatórios, pode ser suficiente ter em mente que as primeiras recopilações espanholas de decisões reais relativas aos assuntos das Índias do fim do século XVI e início do XVII (as assim chamadas Cedulario de Diego de Encinas de 1596 e o esboço da Recopilación de Antonio León Pinelo de 1636) obtiveram suas seleções de uma quantidade estimada de 15000 documentos. Elas foram motivadas principalmente pelo fato de que, já nos anos 70 do século

9 O memorial do primeiro bispo de Manila, Domingo de Salazar, enviado ao Imperador, é citado em Moutin (no prelo), "Y atrévome a decir esto porque, aunque Vuestra Magestad tiene tan cerca de si tantos y tan excelentes letrados en todas las facultades, pero para determinar muchas cosas de Indias, sin duda es menester haber estado en ellas, y no pocos años." 
XVI, nem mesmo os membros do corpo governamental, o Consejo de Indias, tinham uma visão clara da estrutura normativa relevante ${ }^{10}$.

Em síntese, atores de todos os níveis da sociedade se viam simultaneamente confrontados com a necessidade de regulamentar novas situações e uma saturação de informação de difícil domínio. Havia, como é frequentemente o caso em história do direito, simplesmente "muito por saber" e, ao mesmo tempo, carência de soluções precisas para o caso em questão ${ }^{11}$. Essa condição geral de incerteza desencadeou diferentes estratégias de enfrentamento, algumas das quais já eram conhecidas no passado, e outras se desenvolveram sob as novas condições de expansões, a imprensa, as reformas e o Estado da Idade Moderna. Surgiu uma onda de escritos sobre methodus, novas teorias para lidar com conhecimentos normativos inseguros - como o probabilismo, seus precedentes e variações; inovações técnicas - como os novos mecanismos de busca; e novos gêneros literários. Os Estados dos primórdios da Modernidade, assim como a Cúria e as ordens religiosas se engajaram em reformas abrangentes de seus procedimentos e estruturas institucionais. Para o indivíduo, no entanto, a multitudo de conhecimento normativo sobre o qual era possível se apoiar deveria ser dominada. Notadamente livros especializados, oferecendo panoramas das diferentes soluções possíveis, como a ajuda prometida pelo gênero de differentiae e os diversos compendia, epitomizações e summae que eram o núcleo do que nós chamamos "literatura normativa pragmática" são parte dessa multiplicidade de respostas à saturação de informação do início da Modernidade e da resultante insegurança estrutural sobre o conhecimento relevante. O levantamento de Meyer sobre a epitomização como prática erudita na longuedurée e o estudo de caso de Bragagnolo sobre um dos bestsellers da segunda metade do século XVI, o manual de confissão de Martín de Azpilcueta, destacam a variedade destas estratégias de enfrentamento (capítulos 2 e 6).

Para resumir, ordens normativas - ao menos, mas talvez não apenas, na tradição europeia - podem ser compreendidas como resultado de processos diacrônicos e recursivos de tradução de conhecimento normativo, uma prática textual intimamente conectada à história dos meios de comunicação em que esse conhecimento era depositado. Conhecimento normativo novo foi continuamente produzido por uma variedade de atores e entrou neste processo de looping e feedback, abrindo espaço para a diferenciação e especialização, localização e regionalização por e para específicas comunidades epistêmicas e comunidades

10 Ver, sobre o Cedulario de Encinas, García-Gallo (1992), com um panorama da insegurança do conhecimento nos idos de 1570. Sobre a posterior Recopilación de Pinelo, ver Sánchez Bella (1992, vol. 1, p. 32). 11 Sobre a saturação de informação no início da modernidade, ver Blair (2010). 
de prática. Ao mesmo tempo, as práticas de tradução de conhecimento, elas mesmas também parte do conhecimento normativo, experienciaram um processo similar de estabilidade e adaptação.

\section{TRADUÇÕES}

A visão geral da evolução das ordens normativas no tempo, compreendida como um processo contínuo de tradução de conhecimento normativo, mostra que havia a necessidade de literatura pragmática enquanto resposta à saturação de informação. Ela também nos aproxima, mas não é suficiente, para compreender como essas traduções aconteceram em um nível concreto e no regime histórico específico de produção de conhecimento que nós estamos considerando. Ao menos para fins analíticos, pode ser útil distinguir dois momentos. Primeiro, quando a informação normativa é traduzida em conhecimento normativo por certas comunidades epistêmicas através da incorporação desta informação em um contexto diverso, e, segundo, quando este novo conhecimento normativo gerado é traduzido por membros de uma comunidade de prática decidindo em um caso específico.

\subsection{Da informação normativa ao conhecimento normativo}

A primeira tradução ocorre quando a informação normativa é capturada e então inserida em um contexto específico. Essa transformação de informação em conhecimento é estreitamente conectada à forma da comunicação, já que o depósito em um certo meio combina a informação normativa com um certo campo de ação e então adiciona uma camada de significância à informação ${ }^{12}$.

\footnotetext{
12 Dentro do vasto debate sobre "informação" e "conhecimento" e de definição entre os dois, nós optamos por uma distinção que considera informação como a unidade básica, compreendida como dados com relevância e propósitos gerais. Informação é convertida em conhecimento assim que é contextualizada e integrada em um campo de ação, abrindo possibilidades de ação. Desse modo, conhecimento pode ser entendido como a totalidade de todas as proposições que os membros de um grupo consideram verdadeiras ou que são consideradas como verdadeiras em uma quantidade suficiente de textos neste grupo, abrangendo todos os padrões de pensamento, orientação e ação. Ele abrange também o conhecimento implícito, inserido em práticas, rotinas organizacionais; ver, por exemplo, sobre as diferentes definições, Neumann (2013, p. 811), e a bibliografia citada anteriormente, especialmente Wehling (2007). É uma definição mais restrita que aquela utilizada por Renn e Hyman (2012, p. 21-44), que definem conhecimento como a capacidade de um indivíduo, grupo ou sociedade para resolver problemas e antecipar mentalmente as ações necessárias, um potencial de resolução de problemas; eles oferecem uma lista interessante de formas de representação e transmissão de conhecimento. Para um panorama sistemático, ver também Abel (2014). Conhecimento "normativo" refere-se ao conhecimento como possibilidades positivamente identificadas, uma definição que Christoph Möllers (2015) desenvolve em seu Die Möglichkeit der Normen.
} 
Essa incorporação em um contexto mais ou menos específico pode ser vista como uma primeira tradução no sentido amplo do termo, porque a informação normativa, desincorporada de seu contexto factual e temporal pelo depósito em um meio de comunicação, é propensa a adquirir novo significado. Incorporar, por exemplo, informação normativa originada de esferas religiosas em um meio jurídico torna provável que a informação normativa será agora lida como uma informação jurídica, com consequências relevantes para os métodos e práticas de interpretação a serem utilizados. Em outros casos, a incorporação em um contexto institucional específico, como ordenações formuladas por bispos e aprovadas pelo Rei (Rex Galindo, capítulo 9) ou como uma instrução autorizada pela Inquisição (Mejía, capítulo 10), implica que a informação normativa incluída em um meio de comunicação agora goze da autoridade atribuída ao seu formato ou editor, compilador ou às autoridades que recomendam seu uso. O conhecimento normativo incluído na seleção é então carregado de autoridade, enquanto outras opções normativas se tornam menos autorizadas. Para a América hispanocolonial, o exemplo mais famoso para esta atribuição de autoridade a alguns textos e para a desautorização de outros pode ser a Recopilación de Leyes de los Reinos de las Indias de 1680, uma coleção que não derrogou a legislação real não incluída, mas que teve um claro efeito gargalo para a sobrevivência do conhecimento normativo.

Frequentemente, essa autorização e desautorização de conhecimento normativo não ocorre por seleção ou pela simples escrita local, como Honores mostra (capítulo 4), mas explicitamente, por exemplo, nas deliberações sobre diferentes possiblidades de solução para um problema, um típico modelo de raciocínio não apenas na tradição de argumentação escolástica. Não obstante o fato de que essa contraposição de autoridades seja específica para a literatura erudita, pelo menos na tradição escolástica, nós também podemos encontrar essas autorizações e desautorizações em textos menores, incluindo naqueles focados neste volume. "Eu não aprovo a opinião daqueles que [...]", escreve, por exemplo, o primeiro bispo do México em sua Doctrina breve y muy provechosa (1543-1544), como Egío (capítulo 7) mostra, tornando claro que uma doutrina formulada para os infideles na Europa não se deveria aplicar aos povos indígenas em sua diocese ${ }^{13}$. Outros capítulos neste volume contêm exemplos similares de autorizações - por exemplo, no Terceiro Concílio Provincial Mexicano de 1585 (capítulo 8). Resumidamente, indivíduos ou grupos que podem ser considerados, por diversas razões, como parte de comunidades epistêmicas, como membros de uma ordem religiosa ou vice-reis selecionando normas relevantes para os seus domínios, contribuíram

13 Neste volume, ver a nota 59 de Egío (capítulo 7). 
para a tradução de informação normativa em conhecimento normativo pela ação de inserção dela em seus excertos, cópias manuscritas e livros. Frequentemente, esses textos eram especificamente feitos para práticos.

\subsection{Conhecimento normativo na prática}

Esse conhecimento normativo recontextualizado, produzido para contextos de ação específicos e para comunidades de prática específicas, foi o ponto de partida para essas comunidades resolverem casos individuais. De uma (justificadamente contestada) perspectiva moderna, esse processo de descoberta de uma solução correta para um caso específico é frequentemente entendido como uma operação lógica denominada subsunção, associando-se à noção de silogismo ${ }^{14}$. Dando mais atenção às fontes do início da Modernidade, entretanto, nós podemos identificar um modelo completamente diferente de raciocínio, uma especial ars inveniendi. Esse modo de raciocinar pode ser compreendido como uma segunda tradução em que a estrutura normativa - segundo a qual uma decisão era feita - deveria ser gerada desde o conhecimento normativo existente no momento anterior ao que as autoridades selecionadas eram sopesadas uma contra a outra à luz do caso específico, novamente recorrendo ao conhecimento normativo frequentemente incorporado em práticas e resultando na produção de uma declaração normativa para o caso individual.

A lógica dessa ars inveniendi só se torna compreensível se nós tivermos em conta suas premissas epistemológicas implícitas de que os textos, aos quais alguém pode recorrer, não continham solução prontas para todos os casos, mas que todos eles eram concretizações, parte de e um caminho para uma verdade objetiva maior, que não poderia ser acessada diretamente. Como celebremente colocado pelo Digesto no início de seu título final (Dig. 50.17.1): Non ex regula ius sumatur, sed ex iure quod regula fiat - "O direito não é derivado da regra, mas é do direito que deriva a regra". Era possível, em outras palavras, encontrar uma solução justa para cada caso procurando nos textos autorizados, e essa é a razão pela qual se tinha que têlos, ou pelo menos uma seleção deles, à mão. A solução, no entanto, não era arrancada diretamente das autoridades, mas tinha que ser encontrada por meio de um processo racional que utilizava diversas autoridades e sopesava criticamente a sua aplicabilidade e adequabilidade ao caso em questão. Autoridades do passado e a produção normativa corrente dos soberanos eram obviamente argumentos sopesados. Eles mostravam um caminho, talvez

14 Para uma crítica a esse modelo silogístico e para uma clara introdução a esta 'concretização', mais próxima ao que podemos observar na prática dos primórdios da Idade Moderna, ver Vesting (2018, p. 109-114). 
até o único caminho, para achar a solução correta. Mas eles eram, ao fim e a cabo, apenas uma ajuda e não uma propriamente uma solução. Para esse processo de produção da solução correta, eruditos desenvolveram certas regras, um methodus e uma teoria de fontes jurídicas e seu valor autoritativo. Nós podemos chamar isso de "teoria da prática". De acordo com essa teoria, era necessário procurar em diferentes locais (loci, topoi) pela opção normativa cuja verdade parcial parecesse mais apropriada ao caso individual em tela. $\mathrm{O}$ plano de fundo filosófico desse método era a topica - jurídica, filosófica e teológica - do início da Modernidade, e o processo resultante, a dialectica. O methodus provia técnicas específicas de interpretação ${ }^{15}$.

Entretanto, não foram somente essa teoria sobre a prática, a teoria das fontes e o método que influenciaram na produção de uma decisão. De particular importância eram as práticas de produção de normas por si só, fatores muito além da 'teoria sobre a prática', como os padrões de ação estabelecidos, convenções ou conhecimento implícito sobre como proceder corretamente. Essas práticas eram também parte do conhecimento normativo ${ }^{16}$. A pesquisa histórica recente tem crescentemente dado atenção a esta dimensão normativa - i.e., as regras de prática, racionalidades regulatórias, entendimentos implícitos, normas estéticas como estruturas de pensamento, "habitus" etc. - que frequentemente se resumem sob o título de praxiologia $[\text { praxeology }]^{17}$. Seu significado não pode ser superestimado na pesquisa histórica em direito, especialmente em um regime de produção de conhecimento que deixa grandes margens de discricionariedade aos atores (como era o caso dos impérios ibéricos da Idade Moderna), compartilhando assim uma característica geral que também pode ser encontrada na 'teoria sobre a prática', com sua ampla compreensão de significados, amplas regras de interpretação e sua abrangente necessidade de encontrar soluções justas.

São pelo menos essas regras inerentes à prática, as 'práticas da prática', que constituem comunidades de prática: grupos que compartilham um certo consenso sobre como traduzir o conhecimento normativo em uma decisão para um caso concreto. Esses grupos podem ser idênticos às comunidades epistêmicas mencionadas acima, que produziam

15 Essa teoria sobre a prática, abrangendo reflexões sobre a teoria das fontes do direito, o método e a interpretação do direito, foi o objeto central da pesquisa em história do direito sobre a história da metodologia jurídica da Idade Moderna. Sobre esse período, ver, especialmente, o estudo seminal de Schröder (2012). 16 Ver, sobre isso, James Boyd White, que define conhecimento jurídico "como uma atividade da mente, uma forma de fazer algo com as regras e casos e outros materiais do direito, uma atividade que é ela mesma irredutível a um conjunto de diretrizes ou a qualquer descrição fixa. É uma espécie de competência cultural, como aprender uma linguagem; essa pode ser, de fato, a analogia mais próxima que nós temos, já que o que um advogado sabe, no fundo, é como falar e escrever a linguagem do direito em situações atuais no mundo - como usar a linguagem jurídica para criar significado jurídico" (White, 2002, p. 1399). 17 Ver, sobre isso, com referências adicionais, as contribuições em Duve (2017b). 
literatura pragmática para uma área, grupo ou propósito específicos. Entretanto, eles também podem simplesmente estar unidos por suas preferências por certos textos e pela forma de utilizá-los; não é por acaso que, como vários capítulos nesse volume mostram, Concílios da Igreja e ordens religiosas obrigavam os membros de seus grupos a adquirir certos textos e a tê-los à mão. Em todo caso, membros das comunidades ou não, aqueles que tinham de produzir uma decisão em um caso específico, como confessor, juiz ou conselheiro, tinham de usar, em sua prática artesanal de encontrar a resposta correta, certos textos que os provessem com a informação relevante sobre o conhecimento normativo sobre o qual eles elaborariam sua tarefa.

Se uma decisão sobre um caso específico era feita com base nessa ars inveniendi, que era baseada num conceito jurídico material, não-formal, e em algumas regras operacionais (i.e., de uma teoria da prática) e suas práticas correspondentes (i.e., as regras de prática), então uma nova declaração normativa aparecia, ajustada ao caso concreto; uma norma casuística particular. Essa nova declaração normativa, no entanto, não só resolvia o caso. Se capturada em um meio de comunicação - como em uma coleção de decisões ou num manuscrito que sumarizava boas práticas para autoridades públicas, precedentes etc. -, ela também passava para um corpo geral de informação normativa, sendo então descontextualizada e processada em conhecimento normativo, até se tornar, novamente, um objeto de tradução por uma comunidade de prática. Esse processo recursivo é, então, contínuo, constantemente adicionando e mudando a composição da informação normativa processada e convertida em conhecimento normativo: "Conhecimento jurídico é, então, constantemente criado e recriado de formas diferentes por mentes diferentes em ocasiões diferentes" ${ }^{18}$. Em alguns casos, podemos observar algo como a deslocalização do conhecimento normativo local, por exemplo, quando uma ação localmente motivada levou a uma regulação específica que foi posteriormente aplicada a outros casos, ou mesmo incluída na coleção de legislação real, como a Recopilación ${ }^{19}$. Mesmo que a mudança na composição do corpo de conhecimento normativo causada por esses processos de localização e deslocalização do conhecimento normativo possa ter ocorrido em doses homeopáticas e dificilmente perceptível de início, cumulativamente e ao longo do tempo, ela foi considerável. É aqui que nós também podemos encontrar uma pista de como as ordens normativas mudam, pois uma multiplicidade de atores em níveis micro e intermediário produziam conhecimento normativo em suas atividades diárias, continuamente transformando o sistema através de adaptações mínimas.

18 White (2002, p. 1400).

19 Duve (2010). 
A diversidade de corpos regulatórios, chamados aqui 'comunidades epistêmicas', assim como a ars inveniendi praticada por eles atuando enquanto 'comunidades de prática', são elementos-chave do que alguns jus-historiadores, olhando para a esfera secular, descreveram como "cultura jurisdiccional"20 do início da Modernidade. Essa cultura jurisdicional refletia a estrutura 'plural' das sociedades medievais e protomodernas, espelhadas em suas múltiplas iurisdictiones, abrangendo das jurisdições das corporações às jurisdições reais e imperiais. A tensão entre essas jurisdições era constitutiva para sociedades do início da Modernidade, pois em uma ordem normativa sem uma separação de poderes, no sentido moderno, estender a esfera de jurisdição basicamente significava estender poder, e correspondentemente, para o soberano, conceder privilégios jurisdicionais era uma das ferramentas-chave de governo. Ele não era, entretanto, livre na concessão desses privilégios, pois mesmo o soberano estava obrigado a respeitar o direito com suas desde muito estabelecidas regras sobre a distribuição de competências jurisdicionais.

Dentro dessa multiplicidade de jurisdições em diversos níveis, e não obstante um certo exagero dessa divisão na historiografia jurídica, era possível distinguir jurisdições pertencentes à esfera secular daquelas que pertenciam à esfera eclesiástica. Isso não significa que conflitos jurisdicionais ocorriam apenas entre essas duas esferas. Pelo contrário, sob as condições de patronato real, as linhas de conflito frequentemente não corriam sob esta divisa, mas seguiam outras lógicas e contingências históricas. Havia, por exemplo, intensos conflitos entre ordens religiosas e o clero secular, ou entre bispos e membros da Inquisição. Acima de tudo, contudo, todas essas iurisdictiones, seculares ou eclesiásticas, eram fundamentalmente embasadas na ideia de uma ordem divina objetiva de que todas as subordens humanas podiam ser derivadas. Tanto o direito canônico quanto o secular estavam sujeitos a essa ordem divina, dando uma esmagadora importância à religião na produção de conhecimento normativo nos impérios ibéricos. Por essa razão, era importante para toda a economia do conhecimento inerente a essa cultura jurisdicional o momento em que, no início do século XVI, entrava em cena um novo produtor de conhecimento normativo - e importante provedor de literatura pragmática -: a teologia moral.

20 Ver, por exemplo, Garriga Acosta (2006) com referências à rica tradição de reflexão sobre a significância do conceito de iurisdicitio na história do direito europeia, desenvolvida por Pietro Costa, Paolo Grossi, Bartolomé Clavero, António M. Hespanha, Carlos Petit e Jesús Vallejo durante as últimas décadas e posteriormente desenvolvida por Marta Lorente, Alejandro Agüero entre outros. 


\section{CONHECIMENTO NORMATIVO RELIGIOSO E SECULAR}

As razões para a ascensão da teologia moral como uma disciplina acadêmica independente e como uma produtora de conhecimento são variadas e intimamente conectadas com as múltiplas transformações históricas das primeiras décadas do século XVI, mencionadas acima: reformas, expansões europeias, revolução dos meios de comunicação e a ascensão do Estado na Idade Moderna, crescendo principalmente pela absorção de competências jurisdicionais tradicionalmente reivindicadas pela Igreja ${ }^{21}$.

Sem entrar em detalhes, é importante ressaltar que, nessa situação histórica, a Igreja Católica e seu direito ficaram sob considerável pressão. Evidentemente, o direito canônico continuava indispensável quando pessoas eram batizadas, ou se casavam, ou jejuavam, faziam celebrações ou eram enterradas; ele ainda marcava as passagens entre os diferentes estágios da vida cristã. O bispo, cuja posição era fortalecida pelo Concílio de Trento, continuava a exercer sua jurisdição no assim chamado forum externum: na corte eclesiástica, dentro da estrutura de suas visitas ou em sínodos. Juízes delegados e um bom número de encarregados de ofícios eclesiásticos, autoridades e instituições, como também comunidades religiosas, hospitais, abrigos e vários outros, continuaram a viver sob o direito canônico em uma base cotidiana.

No entanto, sob vários aspectos, a jurisdição da Igreja foi reduzida. Em resposta, a Cúria Romana desenvolveu um sistema de governo indireto, incluindo a adoção de práticas políticas e administrativas lembrando aquelas dos Estados seculares do início da Modernidade - por exemplo, ao expandir o sistema de nuntii em cortes imperiais e reais ou intensificando a comunicação com as Igrejas nacionais emergentes. A tentativa de padronizar o conhecimento normativo - por exemplo, regulando a produção dos trabalhos de catequese, como se discute na contribuição de Egío (capítulo 7), seja pela literatura de devoção, como Mejía mostra em seu capítulo sobre a Inquisição na Cartagena de Índias (capítulo 10) ou pelo requerimento de aprovação curial de decretos sinodais -, tudo era parte disso ${ }^{22}$.

Nesse contexto, a importância da doutrina em direito canônico enquanto produtora de conhecimento normativo diminuiu, especialmente em razão do fortalecimento da centralidade da Cúria Romana e suas novas instituições, introduzidas após o Concílio de Trento, e de medidas específicas, como a proibição de comentários sobre os decretos do concílio. $\mathrm{O}$ conhecimento normativo produzido pela Igreja continuou a operar além da esfera eclesiástica

21 Para um panorama desses processos, ver Prodi (2000).

22 Albani; Pizzorusso (2017). 
pela autoridade da tradição. Ele continuou parte das opções normativas disponíveis, às quais se poderia recorrer enquanto fonte do direito, como ratio scripta e como corpo de práticas jurídicas eruditas. Não obstante, ele já possuía uma significância completamente diferente daquela que existia na Alta Idade Média.

Foi nessa configuração histórica que o conhecimento normativo, desenvolvido para o assim chamado forum internum ou forum conscientiae - frequentemente relacionado à prática da confissão, mas não confinado a ela -, cresceu em importância, enquanto que a teologia moral emergia como um novo produtor de conhecimento normativo para esse forum internum $^{23}$. $\mathrm{O}$ conhecimento normativo produzido por essa disciplina em torno do forum internum foi visto como não menos jurídico que o direito canônico praticado no forum externum. O confessor era considerado um juiz das almas, o iudex animarum, e a confissão era equiparada a um procedimento judicial: os decretos do Concílio de Trento explicitamente chamavam a absolvição um actus iudicialis ${ }^{24}$.

Como consequência, o equilíbrio entre diferentes recursos normativos da esfera religiosa modificou o direito canônico para a normatividade produzida para o forum internum, que se tornou um componente-chave da economia normativa nos impérios ibéricos. Ao final do século XVI, quem estivesse procurando pela resposta correta para um problema tinha de tomar nota de importantes textos de teologia moral. A importância da teologia moral como produtora de conhecimento normativo na América Ibérica emerge de forma particularmente clara nas contribuições de Machado Cabral (capítulo 5) sobre a América Portuguesa, nos capítulos de Egío (capítulo 7), Moutin (capítulo 8) e Rex Galindo (capítulo 9) sobre o México e na pesquisa de Danwerth sobre a presença desses textos na América Ibérica (capítulo 3). Eles também apontam para o fato de que havia uma instituição notável, também comunidade epistêmica e comunidade de prática, que dominou a produção de conhecimento normativo nesse campo por mais de um século, ao menos nos mundos ibéricos: a assim chamada "Escola de Salamanca". Um olhar mais atento para esta escola pode nos ajudar a compreender as conexões entre teologia prática (moral), seu raciocínio normativo e, consequentemente, a função e significância da literatura pragmática lá estabelecida.

23 Sobre essa fundação, ver Mahoney (1989); para a significância do forum internum, ver por exemplo, O’Banion (2012) e Marcocci (2014).

24 No texto da sessão do Concílio de Trento dedicado ao sacramento da confissão, os penitentes são vistos como réus submetidos a um julgamento, "ante hoc tribunal tanquam reos", a confissão é equiparada a um julgamento e o confessor a um juiz: "ad instar actus iudicialis, quo ab ipso velut a iudice sententia pronunciatur", ver Concílio de Trento, sessio XIV, 25.11.1551, doctrina, cap. II, VI (ed. Alberigo, Dossetti et at., Conciliorum Oecumenicorum Decreta, edition tertia, 1973), citada de acordo com o texto em Wohlmuth (2001), menções nas p. 704 e 707. 


\section{TEOLOGIA PRÁTICA E LITERATURA PRAGMÁTICA}

A significância da Escola de Salamanca como rede de produção de conhecimento normativo e de literatura pragmática pode, à primeira vista, parecer surpreendente, pois nós normalmente associamos a Escola com grandes tratados de diversos volumes, De iustitia et iure e De legibus de Domingo de Soto, Luis de Molina e Francisco Suárez. Entretanto, os teólogos da Universidade de Salamanca e do Convento dominicano de Santo Estêvão - o núcleo da assim chamada "Escola de Salamanca" -, não habitavam uma torre de marfim, produzindo seus sistemas teóricos em reclusão do mundo, apenas para acadêmicos ${ }^{25}$.

Junto ao seu trabalho teórico, os teólogos de Salamanca e alhures estavam profundamente imersos na prática e na vida real. Nas turbulentas décadas das expansões, reformas, guerras, especulação financeira e inflação do Século XVI, as pessoas eram atingidas por dúvidas morais e procuravam por aconselhamento. Elas enfrentavam problemas da vida cotidiana ou da alta política, a respeito de preços justos, transações financeiras e regras para jejuar. Elas estavam inseguras sobre se era justificado o uso da força contra povos indígenas insurgentes, se prisioneiros das conquistas poderiam ser escravizados e se havia um direito legítimo de levantar espólios. Era essa necessidade de aconselhamento moral, a preocupação com questões religiosas, esperanças escatológicas e medos, junto com uma renovação da teologia, assim como o impacto de personalidades como Francisco de Vitoria, Domingo de Soto e Melchior Cano, que preparam o cenário para a emergência de Salamanca como um dos centros da nova teologia prática.

Naturalmente, vários dos problemas a serem resolvidos não eram novos. Usura, guerra ou fraude foram tópicos clássicos de reflexão normativa por séculos. Entretanto, a mobilização intelectual na Península ibérica durante a primeira metade do século XVI, as intensas querelas sobre o método teológico correto e a incerteza causada pela existência de várias autoridades contraditórias - que ficaram visíveis com o crescente corpo de conhecimento normativo depositado cada vez mais em livros -, tornaram necessário repensar o sistema normativo. Ademais, já que procurar a solução correta significava olhar para as circunstâncias específicas de cada caso, considerar o status das pessoas, seu conhecimento e interesses, o objeto de disputa e as consequências da decisão, era preciso ter indivíduos eruditos que pudessem performar essa reflexão. Em casos de dúvida, a opinião de um expert era indispensável. Francisco de Vitoria afirma isso claramente no início de seu famoso

25 Nesta seção, estou valendo-me de "The School of Salamanca" (Duve, 2020, no prelo). 
Relectio sobre as Índias: "Efetivamente, para uma ação ser boa, se há causa para dúvida, é necessário praticá-la conforme o aconselhamento e determinação de um homem sábio"26.

Os homens sábios - sapientes - eram, em primeiro lugar, teólogos, principalmente em razão de sua experiência confessional e seu tirocínio em teologia prática e na tradição das summae confessorum. Os sapientes eram, então, de fato, também práticos. Além disso, assim como os teólogos, eles se sentiam não apenas autorizados, mas também obrigados a aconselhar os fiéis: seu principal dever era assegurar a salvação das almas e isso os empoderava a dar sua opinião em qualquer problema que envolvesse questões de certo ou errado. De acordo com Vitoria, "a tarefa e ofício do teólogo eram tão abrangentes que nenhuma prova, nenhuma consideração, nenhum tópico parecia estar além da competência da profissão e ofício teológico" 27 . Afirmações similares podem ser encontradas em Domingo de Soto $^{28}$ ou em textos posteriores, como o De Legibus de Francisco Suárez, para citar apenas os autores mais famosos ${ }^{29}$.

Desde esse ponto de vista geral, e especialmente em casos como aqueles dos nativos americanos, os direitos secular e canônico eram meras ciências auxiliares para os teólogos. É claro, era necessário conhecer ambas, mesmo que apenas em razão de suas implicações práticas, como tanto juristas quanto canonistas enfatizavam. Pelo menos a tradição do ius commune provia importantes pontos de vista que tinham de ser enfrentados, como o canonista Martín de Azpilcueta salientou ao tentar limitar as pretensões dos teólogos ${ }^{30}$. Obviamente, a questão de quem era qualificado para dar opiniões em todos os assuntos era também uma

\footnotetext{
26 Francisco de Vitoria, Relectio [...] quam habuit [...] anno a dominica incarnatione millesimo quingentesimo trigesimo nono [...]: "Et in his omnibus ita res se habet, quod si quis antequam deliberauerit, \& legitimè illi constiterit tale factum licitum esse, aliquod tale faceret, \& fortè secundum se esset licitum: talis peccaret, neque excusaretur per ignorantiam: cùm illa, ut patet, non esset inuincibilis, postquam ille non facit quod in se est, ad examinandum quòd liceat, aut non liceat. Ad hoc enim ut actus sit bonus, oportet si aliâs non est certum, ut fiat secundum diffinitionem \& determinationem sapientis. Haec enim est una conditio boni actus [...]." (VITORIA, 2018, p. 288).

27 Francisco de Vitoria, Relectio [...] de potestate civili: "OFFICIVM, ac munus Theologi tam latè patet, ut nullum argumentum, nulla disputatio, nullus locus alienus uideatur à theologica professione, \& instituto." (VITORIA, 2018, p. 174).

28 Soto (1566), f. 05: “[...] Neque vero est quod Theologis vitio detur, hanc sibi assumere provinciam quae Iurisperitis accommodatior videri potest: quandoquidem Canonica iura ex visceribus Theologiae prodiere: Civilia vero ex media morum Philosophia. Theologi ergo est iuris Canonici decreta ad normam Euangelicam exigere; philosphique Ciulia ex principiis philosophiae examinare [...]".

29 Suárez (1613 [2019]), Prooemium, f. 02: "Nulli mirum videri debet, si homini Theologiam profitenti leges incidant disputandae $[\ldots]$...

30 Azpilcueta (1569), Dist. 6., Cap. I, § caveat, n. 11, p. 188: "De iustitia enim Theologi generatim discere sciunt, quid illa est, \& quotuplex, an sit virtus cardinalis, an omnium moralium potissima, in qua potentia locanda, \& alia id genus, quae parum aut nihil confessario conferunt. Quod item iniustitia sit peccatum mortale, facile definire norunt. At definire, quando in iudiciis, in contractibus, in ultimis voluntatibus, et nonnunquam in delictis committatur iniustita in casibus innumeris, qui praeter legem naturae occurrunt, vires Theologi excedit: nisi legum quoque se peritum fecerit."
} 
batalha entre as disciplinas dedicadas à normatividade - direito secular, direito canônico, teologia (moral) e filosofia. No entanto, como discípulo de Vitoria, Melchior Cano, colocou em seu fundamental trabalho De locis theologicis, ao fim e ao cabo, que as auctoritates dos juristas eram irrelevantes para os teólogos em questões de fé e de pequena ou nenhuma relevância em respeito às normas que podiam ser derivadas da lex evangelica ou da ratio. A única área em que eles podiam ter utilidade era em casos de dúvida sobre moribus ecclesiae \& religionis $^{31}$. Em geral, contudo, os teólogos sabiam melhor, e essa é a razão de ser característico da Escola que seus membros davam conselhos em conversas pessoais, nas opiniões escritas de experts ou como iudices animarum no confessionário, mas também através de seus livros com um propósito pragmático inerente - outro exercício de teologia prática.

Alguns desses livros eram mais, outros menos, úteis na prática, a depender em que tipo de 'prática' estava em causa. Mesmo se Domingo de Soto, por exemplo, assegurasse que escrevera seu tratado de vários volumes, De iustitia et iure, publicado em 1556, principalmente em virtude da imperiosa necessidade de dar orientação em assuntos práticos como usura e para a salvação das almas ${ }^{32}$, suas elaborações eruditas em Latim podem não ter servido para todas as comunidades de prática. Mercadores que queriam saber precisamente que tipo de contratos era imoral e, portanto, ilegítimo, podem ter preferido buscar no Tratos y contratos de mercaderes de Tomás de Mercado, escrito pelo frei mexicano dominicano por petição dos mercadores de Sevilha e impresso em Salamanca poucos anos depois, em $1569^{33}$. Isso levanta questionamentos de como definir 'literatura normativa pragmática'. Por que não incluir, por exemplo, o De iustitia et iure de Domingo de Soto, e por que Tratos y contratos de Tomás de Mercado ou Manual de confessores de Martín de Azpilcueta?

\footnotetext{
31 Cano (1563), Liber octavus, Caput Septimum, f. 284: "Prima conclusio: In his, quae ad fidem pertinent, iurisconsultorum auctoritate theologus non eget [...]"; Cano (1563), De locis Theologicis, f. 285: "Secunda conclusio: In his etiam, quae ad mores pertinent, quatenus vel lex evangelica, vel ratio Philosophiae de huiusmodi praescribit, iureconsultorum auctoritas parum aut certe nihil theologo conferrre potest"; Cano (1563), f. 285-286: "Tertia conclusio. In tertio illo genere rerum, ubi scilicet de moribus ecclesiae \& religionis institutis per leges [...] iurisperitorum omnium communis consensus concorsque sententia, theologo magnam fidem facere debet."

32 Soto (1556), Liber VI, Prooemium, f. 505: "Eo denique destinati operis perventum nobis est, cuius praecipue gratia de illo coepimus cogitare. Haec inquam usurarum, contractuum, cambiorumque ac simoniarum sylva in animum potisssime nobis induxit, ut tantam operem molem aggrederemur"; ver, também: Soto (1556), Prooemium, ante Lib. I., f. 05: “[...] peperit tamen humana libido per temporum iniquitatem, parturitque in dies novas fraudulentiae formas, quibus contra ius \& fas suam quisque expleat insatiabilem avaritiam. Quapropter nihil aliud quam operae pretium arbitrandum est si iniqua pacta \& conventa, $\&$ cambia, tamquam adeo multa usurae simoniaeque recentia genera in animum nobis induxerunt, nova de re veteri volumina aedere." 33 Ver o prefácio em Mercado (2019).
} 


\section{LITERATURA NORMATIVA PRAGMÁTICA: DESCRIÇÃO E DEFINIÇÃO}

Tomando a função de um texto em um contexto concreto de uso como o critério definidor para um tipo de literatura, como estudos literários sugerem ${ }^{34}$, e seguindo o que foi dito até agora, literatura normativa pragmática pode ser definida desta forma: textos escritos usados por práticos, em um caminho imediato para acessar o conhecimento normativo relevante que é exigido para produzir uma afirmação normativa relacionada à legitimidade da ação humana.

Há algumas implicações a partir dessa definição. Primeiro, como 'texto escrito', a literatura normativa pragmática é distinguida de outros meios de comunicação, como mídias audiovisuais. Essa, por exemplo, na forma de representações pictóricas em retábulos, crucifixos, lienzos ou performances como peças e procissões, eram frequentemente empregadas em missões e para a catequese e eram, portanto, importantes para o transporte e implementação de ideias normativas. Elas eram uma parte relevante do regime de produção de conhecimento no mundo católico do início da Modernidade. Sem dúvida, a literatura pragmática precisa ser lida em sua íntima conexão com esses outros meios, principalmente em seus entrelaçamentos com a oralidade, como no caso dos sermonarios discutidos por Rex Galindo (capítulo 9). Contudo, esses outros meios geralmente serviam a propósitos catequéticos ou educacionais e não eram direcionados aos práticos que eram responsáveis pela produção de declarações normativas.

Em segundo lugar, deve ser notado que a literatura normativa pragmática não é, de forma nenhuma, limitada aos textos impressos. Pelo contrário; grande parte da literatura pragmática normativa provavelmente nunca foi impressa, mas circulava de forma manuscrita: cópias, excertos, resumos ou compilações de documentos relevantes feitas por ou para práticos. Apesar da baixa capacidade de sobrevivência desses textos e da catalogação pobre dos manuscritos sobreviventes, há algumas indicações de que esses textos manuscritos eram

34 Ver Busse (2000). Esse critério também foi utilizado em outros campos, por exemplo, no debate sobre literatura vernacular e sua significância na história do direito alemã - ver a discussão em Schumann (2013, p. 136) ou, na pesquisa em “pragmatische Schriftlichkeit”, ver a ata do Münstersche Mittelalter-Schriften (1989). Em termos gerais, surpreendentemente pouca atenção tem sido dada, em pesquisa em história do direito, à classificação de "tipos de literatura jurídica" mesmo nos (antigos) trabalhos-padrão em história da literatura; ver, e.g., Holthöfer (1977, p. 106 - "'[a tipologia] com referência às formas tradicionais da última Idade Média [foi formulada] exclusivamente com base nas fontes"); de maneira similar, Söllner (1977, p. 514 - “A tipologia segue, em geral, critérios formais"). Troje (1977, p. 634) coloca "tipos de literatura" entre aspas e depois usa o termo "formas de literatura". Tentativas de aplicar métodos quantitativos e uma perspectiva sociológica não levaram a uma imagem clara sobre os critérios para a definição de tipos de literatura; ver, no entanto, Ranieri (1982). Martin Bertram dá um insight a respeito da falta de critérios claros sobre como classificar o que se chama aqui 'literatura pragmática' na historiografia do direito canônico (BERTRAM, 2014, p. 574). 
numerosos e de grande importância prática ${ }^{35}$. No entanto, em razão de que a disseminação de trabalhos impressos no período sob análise era consideravelmente grande - tanto quanto de manuscritos individuais -, e dadas as limitações práticas, nesse volume nós nos concentramos nos textos impressos. Seria importante, entretanto, considerar os manuscritos, especialmente de práticos que frequentemente montavam um conjunto de documentos que consideravam úteis e o usavam como ferramenta para ação.

Quando nós usamos 'normativa", nós nos referimos à 'normatividade' em duplo sentido: primeiro, se refere ao fato de que esses manuais era eles mesmos normativos, significando que eles davam instruções sobre como agir corretamente. Esse caráter normativo, contudo, se aplica a vários textos, de manuais de navegação e livros sobre como exercer o ofício de notário a livros de receitas. Em segundo lugar, e mais importante, eles são normativos no sentido de que contêm conhecimento específico para a produção de uma afirmação normativa. Para isso, nós adotamos uma ampla noção de 'normatividade' que se refere aos preceitos do direito (em um sentido amplo, sociológico) e da religião. Essa ampliação não parece nada além do que a consequência do pluralismo normativo e jurisdicional do início da Modernidade e, principalmente, a importância da religião e os preceitos decorrentes da teologia moral para a cotidiana administração da justiça e tomada de decisões. Consequentemente, literatura normativa pragmática inclui textos que contêm conhecimentos identificados de forma positiva como uma possibilidade de ação ${ }^{36}$. Ela, portanto, consiste não apenas em trabalhos de direito secular, canônico e teologia moral, mas também pode incluir outros textos em que recomendações para ação e conduta correta são guardados, como as literaturas catequética e pastoral, coleções de sermões e livros de devoção. Os capítulos de Machado Cabral (capítulo 5), Mejía (capítulo 10), Moutin (capítulo 8) e Rex Galindo (capítulo 9) provêm exemplos impressionantes da variedade de literatura que entra em cena com esse significado ampliado ${ }^{37}$.

Outra premissa inerente à definição é a de que os destinatários da literatura pragmática eram principalmente aqueles que deveriam estar bem informados sobre o conhecimento normativo relevante, pois tinham de tomar decisões: os práticos. Era esse grupo que precisava

35 Ver as referências de Danwerth (capítulo 3) nesse volume.

36 Para esse conceito amplo de normatividade, ver Möllers (2015). Com isso, nós estamos adotando um conceito mais amplo do que, por exemplo, Dave De Ruysscher (2018) em sua discussão sobre guias de mercadores. 37 Como a literatura pragmática é definida de acordo com a sua função e não com seu campo, essa definição poderia ser aplicada a um amplo conjunto de campos; por exemplo, sobre a literatura normativa pragmática para certas profissões como notários, navegadores, artesãos ou mercadores. Quanto a isso, ver a coleção Hoock, Jeannin (1991, v. 1). Se um manual de mercadores contém conhecimento sobre a legitimidade de certas ações, como contratos, deve ser considerado como literatura normativa pragmática. 
de informações para o exercício da ars inveniendi descrita acima. Obviamente a diversidade de práticos pode ser extremamente alta, a depender da comunidade de prática que tivermos em mente. No entanto, em vista da formação limitada e por razões econômicas, assim como levando em consideração as circunstâncias históricas dos impérios ibéricos, podem ter sido, acima de tudo, usuários profissionais. Os estudos sobre circulação de livros, propriedade de livros (ver Danwerth, capítulo 3) e sobre o uso da literatura pragmática neste volume examinam diferentes tipos de práticos: missionários, mercadores, juristas, mas também leigos.

De certo modo, os usuários eram pragmatici, um termo usado na historiografia jurídica do século XIX por Roderich Stintzing em seu inovador estudo em literatura popular de direito romano-canônico até o século $\mathrm{XVI}^{38}$. Com isso, Stintzing, contudo, recorreu ao uso pejorativo do termo pragmatici como homines quidam forensis professionis que, ao menos desde os dias da ciência jurídica do Humanismo, referiam-se à pessoa que, de alguma forma, trabalhava na prática forense, mas carecia de erudição ${ }^{39}$. As ferramentas desses práticos, a assim chamada literatura 'popular', eram caracterizadas, então, como "ferramentas dos semieruditos" (Hülfsmittel der Halbgelehrten) que, em um certo sentido, é próximo ao que os usuários da literatura pragmática eram em suas respectivas comunidades de prática. Contudo, à medida que o termo 'popular' foi se enraizando em uma discussão filosoficamente carregada sobre a recepção do direito erudito na Europa e foi construída como um contramodelo à literatura 'erudita', ele foi rapidamente criticado como equívoco e como carregado de grande número de implicações ${ }^{40}$. Por essas razões, o termo não é empregado aqui, também para evitar possíveis mal-entendidos que podem aparecer devido às mais recentes conotações de literatura 'popular' enquanto um gênero específico para atores subalternos.

Já para as comunidades de prática que podem ter sido os usuários (pretendidos) desses textos, nós podemos encontrar uma grande variedade. Algumas vezes nós conhecemos a comunidade de prática para que esses livros foram escritos - por exemplo, quando eles são nomeados explicitamente pelos autores, como era o caso de Tomás de Mercado. Entretanto, os capítulos nesse volume mostram vários exemplos de uma produção para comunidades de prática específicas, mesmo quando não foram explicitamente endereçadas nos títulos. Quando o primeiro bispo da Nova Espanha, Juan de Zumárraga, por exemplo, produziu literatura

\footnotetext{
38 Stintzing (1867).

39 Ver, por exemplo, BUDÉ (1556, Reliquae, f. 241v., littera H): "Pragmatici igitur erant quidam forensis professionis"; esse entendimento continuou em trabalhos de referência posteriores, como de Kahl (1749, sub v. Pragmatici, p. 301): "Pragmatici erant homines quidam forensis professionis, qui causarum actores juris ignaros monebant interdum, juris responsa, actionumque formulas subministrantes."

40 Ver, por exemplo, Below (1905, p. 110-112); ver, também, Erler (1984, p. 127-134).
} 
catequética em uma fase-chave da história da Igreja do México (Egío, capítulo 7), ou quando meio século depois, seus sucessores no Concílio Provincial do México novamente tiveram de tomar uma variedade de decisões com o objetivo de selecionar, atualizar e adaptar o conhecimento normativo disponível para as circunstâncias regionais específicas, fica claro que tinham em mente os membros do seu clero. Como Moutin mostra (capítulo 8), eles se dirigem a eles mesmos e a outras partes da população - por exemplo, aqueles que faziam consultas com o Concílio, com diferentes estratégias de comunicação: produzindo cânones de concílio, um manual confessional e outros textos, que hoje descreveríamos como literatura pastoral, mas que continham conhecimento normativo estruturado em diferentes formatos. Machado Cabral (capítulo 5) examina a produção e o uso desses textos por jesuítas no Brasil, e Bragnagnolo mostra a conexão entre traduções e audiências previstas: a primeira versão do manual confessional de Azpilcueta era baseada em um modelo português, enquanto a versão posterior integrou as experiências da primeira missão jesuítica. A partir daí, o próprio autor continuou adaptando seu manual para satisfazer as necessidades de diferentes comunidades de prática (capítulo 6$)^{41}$.

Tendo esses práticos como os principais destinatários em mente, também parece mais apropriado falar de 'literatura pragmática' em lugar do termo 'literatura prática', empregado em estudos mais recentes de história da ciência sobre textos de práticos para práticos - por exemplo, quando a expansão europeia e avanços na astronomia produziram inovações nas técnicas de navegação. A produção desses textos, uma resposta à necessidade de prover informações para práticos menos experientes, mostra alguns paralelos interessantes com a tentativa de prover missionários ou outros encarregados de literatura normativa pragmática. $\mathrm{O}$ interesse em literatura prática da parte de historiadores da ciência, contudo, consiste principalmente em superar a divisão entre conhecimento teórico e prático. Eles, então, focam, sobretudo, na prática como forma de produção de conhecimento e sua contribuição à 'ciência' como o clássico objeto de interesse acadêmico. De fato, a literatura normativa pragmática, em alguns casos, provavelmente serviu uma função similar - o capítulo de Meyer sobre a epitomização aponta nessa direção (capítulo 2) - e podem existir mais exemplos de como a literatura pragmática escrita por práticos levou a importantes inovações; por exemplo, pela abstração e condensação de conhecimento. Entretanto, a literatura pragmática de interesse no nosso contexto foi majoritariamente escrita por autores eruditos (que eram também práticos), com o objetivo de prover práticos menos eruditos com ferramentas úteis para o exercício de

41 Bragnagnolo (2018). 
sua pesquisa pela resposta correta. Assim, de certo modo, a perspectiva histórico-jurídica aqui tomada é inversa ao estudo da contribuição de atores não-eruditos ao conhecimento científico ${ }^{42}$.

Finalmente, o caráter 'pragmático' desses livros é frequentemente expressado em uma semântica da pragmatização, em alguns casos claramente visível nos títulos: Manual, Práctica, Enchiridion, Memorial, Arte, Norte ${ }^{43}$, com interessantes variações de significado, como Casagrande mostra em seu capítulo (capítulo 11). Só alguns desses incluem o termo epitome; mais usam sinônimos latinos, como compendium, breviarium e summarium. $\mathrm{O}$ objetivo de apresentar a seleção e sumário do imenso tesouro de informação normativa, i.e., de coletar o conhecimento relevante, também aparece em subtítulos e paratextos: o conhecimento será apresentado breviter, sumariamente, breve y llana, breves y claras. No Manual de Azpilcueta, encontramos expressões como brevissimamente, summa brevedad, breves y claras, breve memoria etc. (capítulo 6) e, no caso das cartillas usadas na Inquisição em Cartagena de Indias, a forma diminutiva já indica seu formato menor (capítulo 10).

Esses títulos podem ser indicadores úteis sobre como um livro pode ser considerado literatura pragmática ou não, principalmente porque expressam claramente para quem os livros são destinados. Livros de título De iustitia et iure, por exemplo, apelavam para uma audiência diferente ${ }^{44}$ e não serviam de forma imediata para encontrar a solução correta em um exercício prático. Assim como outros tipos de literatura - por exemplo, vocabulários e outras coleções de conhecimento normativo, como comentários -, podem ter sido úteis como instrumentos auxiliares para o raciocínio normativo, mas não diretamente na e para a prática. Em termos de forma, a literatura pragmática frequentemente continha índices e outros dispositivos de busca que eram destinados a facilitar o uso ${ }^{45}$. Mesmo que os títulos dos trabalhos frequentemente mencionassem seu formato acessível, brevidade, facilidade de uso, isso de nenhuma forma era sempre verdadeiro: vários dos sumários aumentavam de novo através de contínuas expansão e adições e, então, se tornavam objetos de epitomização. Porém, como livros feitos para uso prático, eles eram normalmente de formato pequeno.

\footnotetext{
42 Sobre literatura prática da Idade Moderna, ver as contribuições em Valleriani (2017a; 2017b). O termo pragmático pode também se desenvolver em uma pesquisa diferente, mas de algum modo relacionada, sobre pragmatische Schriftlichkeit (ver edição de Keller, Grubmüller e Staubach - MÜNSTERSCHE

MITTELALTER-SCHRIFTEN, 1989). Eles definem o conceito de escrita pragmática (formulada para contextos diferentes) como "todas as formas de uso da escrita e textos que diretamente servem a ações propositais ou que são destinadas a guiar a ação humana pela provisão de conhecimento" (ibid., p. 1). Sobre guias e manuais, ver também Craeger (no prelo). Sou grato a Angela Creager por me dar acesso a esse texto. 43 Um panorama é oferecido por Barrientos Grandón (2000), especialmente p. 260-263. 44 Sobre esses tratados, ver: Folgado (1959), Barrientos García (2001). 45 Blair (2010).
} 


\section{ENTRE O DIREITO NOS LIVROS E O DIREITO EM AÇÃO}

A essa altura, deve ter ficado claro que a literatura normativa pragmática cumpria uma função importante dentro do regime de produção de conhecimento na América ibérica dos séculos XVI-XVII. Era uma importante ferramenta para a ars inveniendi, caracterizada aqui como uma 'segunda tradução', realizada por certas comunidades de prática de uma maneira mais ou menos erudita e culta, de acordo com as circunstâncias concretas. Através de sua seletividade, a literatura pragmática reduziu a escala de conhecimento normativo para um patamar administrável e, assim, respondeu às necessidades dos práticos. A literatura pragmática autorizava algumas partes do conhecimento normativo e desautorizava outras, em vários casos observando as condições locais para que eram feitas. Assim, ajudou a reduzir a incerteza sobre se alguém tinha o conhecimento normativo relevante à disposição. Essa redução de incerteza era também possível pois, muito provavelmente, a literatura normativa pragmática não era tão cara quanto os grandes livros e, portanto, podia ser adquirida de tempo em tempo em versões atualizadas; não é por acaso que vários dos livros pertencentes a esse grupo tiveram várias edições.

Em um nível sistêmico, a literatura pragmática normativa era um meio produzido por comunidades epistêmicas para a seleção e armazenamento do conhecimento normativo para campos concretos de ação - era um produto do que foi chamado de 'primeira tradução', que convertia informação normativa em conhecimento normativo. Desse modo, contribuiu para a implementação do conhecimento normativo e sua reprodução em diferentes contextos locais. Isso poderia ser feito porque ela especificava partes do conhecimento normativo para certas comunidades de prática, por exemplo, para os membros de ordens religiosas, e assim desencadeava processo de diferenciação regional.

Olhando para essas importantes funções, é surpreendente que historiadores do direito não dedicaram mais atenção à literatura pragmática e seu papel nos regimes históricos de produção de conhecimento. Malgrado o fato de que, ao menos desde os dias de Stintzing, historiadores do direito estudando o ius commune e sua literatura jurídica estiveram cientes da existência e significância história desta literatura para os práticos, livros que consideraríamos como literatura pragmática receberam considerável atenção principalmente na história do direito germânica, um campo comparativamente menor depois da Segunda Guerra ${ }^{46}$. A (2007); Schumann (2012; 2013); Wittmann (2015); algumas discussões também em Neuheuser (2011). 
respeito do direito canônico tardo-medieval, apenas recentemente a importância da literatura pragmática foi apontada e menções foram feitas para vê-la como uma ferramenta há muito menosprezada para a implementação e regionalização do conhecimento normativo ${ }^{47}$. Ela é brevemente mencionada em livros de referência como literatura na fronteira entre o direito canônico e a teologia prática ${ }^{48}$, e livros-texto sobre a história do direito canônico listam alguns dos trabalhos dos grandes autores da teologia moral ${ }^{49}$, assim como a história do direito privado moderno ocasionalmente menciona a literatura pragmática teológico-moral, enfatizando sua importância para a recepção do direito romano-canônico em áreas com baixo grau de formação ${ }^{50}$.

Em geral, entretanto, a pesquisa em história do direito, ainda dominada pelo paradigma jurídico-historiográfico da cientifização do direito e da profissionalização dos operadores do direito, não olhou realmente para esses textos em sua funcionalidade para a formação das ordens normativas ou mesmo tentou conceituá-los como gênero ${ }^{51}$. Eles eram simplesmente desinteressantes para uma historiografia traçar o que era visto como o progresso do direito científico para a Modernidade, em uma certa teleologia e com um conceito restrito de direito ${ }^{52}$.

Ao mesmo tempo, a literatura normativa pragmática não era valorizada pela historiografia geral, pois esses textos pareciam não revelar nada sobre o que é às vezes chamado de "direito em ação" - o objeto central da maioria dos estudos históricos sobre os mundos coloniais ibéricos. Os manuais para confessores e outros textos de teologia moral foram basicamente vistos como parte de uma tentativa de disciplinar a população e estabelecer poder colonial, uma função que definitivamente também preencheram. Eles foram, contudo, apenas raramente entendidos como portadores de conhecimento normativo que contribuiu para uma formação [literacia] 'jurídica' geral, permitindo que todas as partes da sociedade colonial, especialmente também os membros dos povos indígenas, se engajassem no discurso sobre seus direitos, como Honores aponta em seu capítulo nesse

\footnotetext{
47 Especialmente Martin Bertram (2014) enfatizou a necessidade de estudar esses textos e criticou o estado da arte.

48 Schulte (1887); Erdö (2006).

49 Por exemplo, Van Hove (1945, p. 566).

50 Bergfeld (1977, p. 1001). Sobre a importância da literatura pragmática para a Escola de Salamanca nesse contexto, Bergfeld (1977, p. 1027-1028).

51 Mais recentemente, a literatura de comentários jurídicos recebeu mais atenção, por exemplo em Jansen (2014); Kästle-Lamparter (2016). Entretanto, essas eram precisamente ferramentas auxiliares para prática erudita, de modo a que novamente o foco está no papel deste gênero literário para a emergência do direito "científico".

52 Ver sobre isso a revisão historiográfica dessa tradição em Duve (2012).
} 
volume $^{53}$. A literatura pragmática, portanto, continuou largamente invisível entre um interesse pelo "direito nos livros", focando quase exclusivamente nos grandes autores e textos levando ao sistema moderno, e a busca pelo "direito em ação", através da pesquisa em registros forenses e outros documentos da prática jurídica. A literatura pragmática normativa nos leva, porém, precisamente para o amplo campo entre essas duas perspectivas reducionistas e pode, se alguém realmente quiser empregar a terminologia estabelecida, melhor ser considerada como "livros jurídicos em ação ${ }^{54}$.

Apenas rara atenção foi dedicada a este gênero em outros campos, tal como a pesquisa em teologia moral na Idade Moderna. Aqui, também, os estudos focaram em grande medida em autores famosos e seus trabalhos ${ }^{55}$. Parte da literatura do século XIX e do início do século XX incluiu breves levantamentos de importantes trabalhos em teologia moral da Idade Moderna $^{56}$, majoritariamente selecionados de acordo com seu valor prático como auctores probati para uso jurídico contemporâneo. Algumas seções introdutórias de livros-textos de teologia moral ${ }^{57}$ contêm alguma informação e, por vezes, a significância histórica dessas opera practica é destacada ${ }^{58}$. Todas essas referências, entretanto, continuam relativamente marginais para a história da disciplina e não foram conectadas à análise do processo de produção de conhecimento normativo.

Estudos sobre a história da teologia, missões e catequeses nas Américas, examinando a produção da recepção de trabalhos em teologia moral, proveram alguns insights interessantes, mas estão majoritariamente focados em tópicos específicos da disciplina, como teologia das missões, doutrina sacramental etc., e não olham para o gênero de literatura pragmática propriamente dito ${ }^{59}$. A pesquisa sobre a Escola de Salamanca também se concentrou em grande medida, no passado, nos grandes autores e tratados, e apenas ocasionalmente em manuais pragmáticos menores. A conexão entre teologia prática e a produção de literatura pragmática ainda não recebeu, no entanto, até onde posso ver, nenhuma atenção acadêmica ${ }^{60}$.

Em pesquisa sobre a história do direito protomoderno na América Latina, Ismael Sánchez Bella examinou a literatura jurídica práctica em um estudo exaustivo, seguido por 53 Sobre os direitos dos povos indígenas e sua participação na negociação colonial, ver Duve (2018b). 54 As recentes publicações em "livros jurídicos em ação", que se concentram principalmente em livros-texto ou tratados, desde a perspectiva do direito comum do século XIX, foca em diferentes aspectos períodos e áreas (ver: Fernandez; Dubber 2012); Fernandez (2018); a discussão de livros-texto e sua autoridade em Simpson (1981) conserva sua importância seminal. 55 Ver, por exemplo, Vereecke (1973) e Vidal (2012).

56 Fuchsius (1848, p. 232-268); Bund (1900).

57 Bouquillon (1903, p. 71-167); Pinckaers (2004, p. 264-288).

58 Ver também Theiner (1970).

59 Saranyana et al. (1999).

60 Ver Duve et al. (2020, no prelo). 
alguns outros, e trabalhos mais recentes mostraram a importância da literatura pragmática no campo do direito processual e criminal em seus estudos sobre cultura jurisdicional ${ }^{61}$. Alguma pesquisa foi feita em livros jurídicos de referência e dicionários ${ }^{62}$, assim como em literatura de ensino e de exame ${ }^{63}$. Contudo, nenhum desses estudos olhou para esses livros em sua funcionalidade no regime protomoderno de produção de conhecimento normativo, ligando sua forma e conteúdo à sua significância específica como ferramentas do império.

Foi António Manuel Hespanha quem mostrou a íntima conexão entre forma e conteúdo na literatura jurídica do início da Modernidade muito claramente, e mais cedo que outros, em um artigo publicado em 2008, e quem colocou a história do método jurídico, tradicionalmente reconstruída majoritariamente como resultado de discussões teóricas, em um contexto de história de meios [media]. Seu objetivo era atrair atenção para o fato de que o que ele chama de duas técnicas dominantes de simplificação do discurso jurídico - "reduzir diálogo à razão" e "substituir direito doutrinal por direito "legal" - têm de ser vistas como profundamente entrelaçadas com condições materiais dinâmicas ${ }^{64}$. Ele distinguiu entre diferentes modelos e mostrou a interdependência entre esses modelos e seu conteúdo. Para ele, estratégias diferentes para lidar com esse excesso de informação na Idade Moderna levaram à emergência de diferentes tipos de literatura. Neste contexto, a crescente produção de índices, trabalhos de referência e outros desenvolvimentos também resultaram no que ele chama de "trivialização" dos livros jurídicos. "Compacidade, legibilidade, simplicidade, ordem: essas agora se tornam as qualidades de um bom livro jurídico, qualidades que são enfatizadas nos próprios títulos", como Liber utilissimus, liber in quo facile explanatur, Manual etc. ${ }^{65}$. Era principalmente essa perspectiva que vários autores dos capítulos desse livro tinham em mente quando eles estavam examinando sua literatura pragmática, colocando esses meios de comunicação [media] específicos em contexto pragmático.

61 Sánchez Bella (1954). Ver, por exemplo, Agüero (2008); Garriga Acosta (2006).

62 Barrero García (1973).

63 Beck Varela (2018).

64 Hespanha (2008, p. 18).

65 Hespanha (2008, p. 31). 


\section{GRANDES IMPÉRIOS, PEQUENOS LIVROS?}

“A Majestade Imperial deve não apenas ser adornada com armas, mas também armada com leis, para que possa governar corretamente tanto em tempos de paz quanto de guerra", comanda a Constitutio Imperatoriam de 533 de Justiniano, antes de afirmar ter trazido paz e fé aos infiéis ${ }^{66}$. No Império espanhol da Idade Moderna, essas sentenças logo do início das Institutiones de Justiniano ressoavam não apenas para juristas. Como tantos outros spolia da Antiguidade e da tradição cristã, a ideia de um imperador que defendia a religião, armado tanto de leis quanto de armas, tinha se tornado parte da linguagem e do imaginário político. $\mathrm{O}$ symbolum IV na coleção de emblemas de Saavedra Fajardo ${ }^{67}$ ilustra isso, assim como as afirmações como a de Castillo de Bovadilla: “A defesa da república consiste em letras, armas e religião" transformações, forneceu uma linguagem comum para legisladores imperiais; mais profundamente, práticas romanas de legalidade [...] permitiam criatividade, considerações abertas e refinamentos do legalismo imperial" ${ }^{69}$ e uma grande amplitude de estudos acadêmicos foi dedicada à reconstrução do uso de conhecimento normativo em debates sobre a legitimação da conquista, o direito internacional ou em contextos mais específicos.

Entretanto, não foi apenas o direito romano que foi traduzido em um processo diacrônico enorme. Nos mundos ibero-americanos dos séculos XVI e XVII, era especialmente conhecimento normativo do campo da religião que fazia o império. Era na vida diária que a ordem normativa colonial se estabilizava e se atualizava outra e mais uma vez, muito além das fronteiras da "cidade letrada", por um número infinito de atores em nível micro e médio ${ }^{70}$. Essa produção de conhecimento teve lugar em diversas localidades imperiais como Madrid, Manila ou México, assim como nas reducciones de indios, em regiões rurais ou em terras de ninguém entre as esferas de influência portuguesa e espanhola. Essa produção de conhecimento normativo não pressupunha nenhuma experiência profunda, mas sim conhecimento normativo elementar. Vários estudos neste volume mostram que tal 66 "Imperatoriam maiestatem non solum armis decoratam, sed etiam legibus oportet esse armatam, utrumque tempus et bellorum et pacis recte possit gubernari", ver Constitutio Imperatoriam, pr. e 1, citada pela edição de Krüger, disponível online em https://droitromain.univ-grenoble-alpes.fr/

67 O Symbolum IV, Non solum armis está contido em Idea principis christiano-politici, centum symbolis expressaa Didaco Saavedra Faxardo [...] - Bruxellae 1649: excudebat Ioannes Mommartius, suis, et Francisci Vivieni sumptibus, 8v, p. 24), online: http://www.fondiantichi.unimore.it/FA/emblem01/ saavg004.html. 68 Ver: Castillo de Bobadilla (1597) Liber I, Cap X, Sumario, 187: La Defensa de la Republica consiste en letras, armas, y religion.

69 Burbane; Cooper (2013, p. 280).

70 Sobre a literacia jurídica, ver Owenby e Ross (2018), Herzog (2015) e, mais especificamente sobre literacia indígena, ver Rappaport e Cummins (2011). 
conhecimento elementar era surpreendentemente difundido, não apenas entre euroamericanos, mas também entre nativos americanos. Um meio central que pode ter tornado a inteligibilidade jurídica básica - e, assim, também a administração imperial e o imperialismo normativo - possível foi a literatura normativa pragmática. Ela era amplamente distribuída e usada, e levantamentos sobre a circulação e presença de livros pragmáticos nos capítulos escritos por Otto Danwerth e Renzo Honores e vários estudos de caso sobre seu uso tornam isso muito claro.

Esses achados suportam a hipótese que deu origem à pesquisa publicada neste volume: a literatura pragmática do campo religioso é particularmente importante se nós quisermos compreender a emergência da ordem colonial enquanto um processo contínuo de tradução de conhecimento normativo, ocorrendo não apenas em alguns centros imperiais como Lima, México, Santo Domingo, mas como parte de uma produção de conhecimento global no campo da normatividade, uma camada amplamente subestimada no processo de glocalização que levou ao mundo moderno.

\section{REFERÊNCIAS}

\section{FONTES PRIMÁRIAS}

AZPILCUETA, Martín de. Commentarii in tres de poenitentia distinctiones posteriores, videlicet V, VI et VII. Lyon: Petri Fradini, 1569.

BOUQUILLON, Thomas. Theologia moralis fundamentalis. 3 ed. Brugis: Beyaert, 1903.

BUDÉ, Guillaume. Annotationes Priores \& Posteriores [...] in Pandectas [...]. Lutetiae: Michaelis Vascosani, 1556. Disponível em: $<$ https://archive.org/details/bub_gb_GkZ_VQtviQC/page/n509>.

CANO, Melchor. De locis Theologicis. Salamanca: Mathias Gast, 1563.

CASTILLO DE BOBADILLA, Jerónimo. Politica para corregidores y señores de vassallos, en tiempo de paz y de gverra. Vol. 1. Madrid: Luis Sanchez, 1597.

KAHL, Johann. Magnum Lexicon Juridicum. Tomus secundus, M-Z. Köln: Cramer, 1749.

MERCADO, Tomás de. Tratos y contratos de mercaderes y tratantes discididos $y$ determinados. Editado por Christiane Birr, Andreas Wagner e David Glück. Série "The School of Salamanca. A Digital Collection of Sources". Direção de série por Thomas Duve e Matthias Lutz-Bachmann. Mainz: Akademie der Wissenschaft und der Literatur, 2019 [1569]. Disponível em: <https://id.salamanca.school/texts/W0007>.

SOTO, Domingo de. De iustitia et iure. Salamanca: Andrés Portonaris, 1556. 
SUÁREZ, Francisco. De legibus ac Deo legislatore. Liber primus: De lege in communi eiusque natura. Stuttgart: Bad Cannstatt: fromann-holzboog, 2019 [1613].

VITORIA, Francisco. Relectiones Theologicaes XII. Editado por Christiane Birr, Andreas Wagner e David Glück. Série "The School of Salamanca. A Digital Collection of Sources". Direção de série por Thomas Duve e Matthias Lutz-Bachmann. Mainz: Akademie der Wissenschaft und der Literatur, 2018 [1557]. Disponível em: $<$ https://id.salamanca.school/texts/W0013 $>$.

\section{FONTES SECUNDÁRIAS}

ABEL, Günter. Systematic Knowledge Research. Rethinking Epistemology. In: SANDKÜHLER, Hans Jörg (Ed.). Wissen: Wissenskulturen und die Kontextualität des Wissens. Frankfurt am Main: Peter Lang, 2014. p. 17-37.

AGÜERO, Alejandro. Castigar y perdonar cuando conviene a la República: la justicia penal de Córdoba del Tucumán, siglos XVII y XVIII. Madrid: Centro de Estudios Políticos y Constituciones, 2008.

ALBANI, Benedetta; PIZZORUSSO, Giovanni. Problematizando el patronato regio: nuevos acercaminentos al gobierno de la Iglesia ibero-americana desde la perspectiva de la Santa Sede. In: Duve, Thomas (Ed.). Actas del XIX Congreso del Instituto Internacional de Historia del Derecho Indiano. Madrid: Dickinson, 2017. p. 519-543.

BARRERO GARCÍA, Ana María. Los Repertorios y Diccionarios jurídicos desde la Edad Media hasta nuestros días. Anuario de Historia del Derecho Español, [S. 1.], v. 43, p. 311352, 1973. Disponível em: http://hdl.handle.net/10261/15019.

BARRIENTOS GARCÍA, José. Los Tratados „De Legibus“ y „De Iustitia et Iure“ en la Escuela de Salamanca de los siglos XVI y XVII. Salamanca: Revista de estudios, n. 47, p. 371-415, 2001.

BARRIENTOS GRANDÓN, Javier. La literatura jurídica indiana y el ius commune. In: ALVARADO PLANAS, Javier (Ed.). Historia de la literatura jurídica en la España del antiguo régimen. v. 1. Madrid: Marcial Pons, 2000. p. 199-286.

BECK VARELA, Laura. 'Memoria de los libros que son necesarios para pasar': Lecturas del jurista en el siglo XVI ibérico. CIAN - Revista de Historia de las Universidades, [S. 1.], v. 21, n. 2, p. 227-267, 2018. DOI: https://doi.org/10.20318/cian.2018.4476.

BELOW, Georg von. Die Ursachen der Rezeption des römischen Rechts in Deutschland. [s.n.]: München, 1905.

BERGFELD, Christoph. Katholische Moraltheologie und Naturrechtslehre. In: COING, Helmut (Ed.). Handbuch der Quellen und Literatur der neueren europäischen Privatrechtsgeschichte: Neuere Zeit (1500-1800). Das Zeitalter des gemeinen Rechts. C. H. Beck'sche Verlagsbuchhandlung: München, 1977. v. 2.1. p. 999-1033. 
BERMAN, Harold J. Law and Revolution: The Formation of the Western Legal Tradition. v. 1. Cambridge (MA): Harvard University Press, 1983.

BERTRAM, Martin. Spätmittelalterliches Kirchenrecht: Vier Anmerkungen zur Forschungslage. Zeitschrift der Savigny-Stiftung für Rechtsgeschichte: Kanonistische Abteilung, Berlin, v. 100, n. 1, p. 563-579, 2014.

BLAIR, Ann. Too Much to Know: Managing Scholarly Information before the Modern Age. New Haven (CT): Yale University Press, 2010.

BÖSCHEN, Stefan. Hybride Wissensregime: Skizze einer soziologischen Feldtheorie. BadenBaden: Nomos, 2016.

BRAGAGNOLO, Manuela. Les voyages du droit du Portugal à Rome. Le 'Manual de confessores' de Martín de Azpilcueta (1492-1586) et ses traductions. Max Planck Institute for European Legal History Research Paper Series, [S. 1.], n. 13, 2018. DOI:

https://doi.org/10.2139/ssrn.3287684.

BUND, Jacobo. Catalogus auctorum qui scripserunt de theologia morali et practica: Compendiosam exhibens notitiam biographicam scriptorum, elenchum operum et judicium criticum de auctoritatis pondere quo singuli auctores in re morali fruuntur. Rouen: Kessinger Publishing, 1900.

BURBANK, Jane; COOPER, Frederick. Rules of law, politics of empire. In: BENTON, Lauren; ROSS, Richard J. (Eds.). Legal Pluralism and Empires: 1500-1850. New York: NYU Press, 2013. p. 279-293.

BURKE, Peter. What is the History of Knowledge?. Cambridge: Polity, 2015.

BUSSE, Dietrich. Textsorten des Bereichs Rechtswesen und Justiz. In: BRINKER, Klaus et al. (Eds.). Text und Gesprächslinguistik: ein internationales Handbuch zeitgenössischer Forschung. v. 1. Berlin: Walter de Gruyter, 2000. p. 658-675.

CLANCHY, Michael T. From memory to written record: England 1066-1307. 2 ed. Oxford: Blackwell, 1993.

CRAEGER, Angela. Learning by the Book: Manuals and Handbooks in the History of Knowledge - introduction to the special issue. The British Journal for the History of Science - Themes (no prelo).

DASTON, Lorraine. The History of Science and the History of Knowledge. KNOW: A Journal on the Formation of Knowledge, [S. 1.], v. 1, n. 1, p. 131-154, 2017. DOI: https://doi.org/10.1086/691678.

DE RUYSSCHER, Dave. How Normative were Merchant Guidbooks? Of Customs, Practices, and ... Good Advice (Antwerp, Sixteenth Century). In: PIHLAJAMÄKI, Heikki et al. (Eds.). Understanding the Sources of Early Modern and Modern Commercial Law: Sources, Statutes, Contracts, and Legal Scholarship. Leiden; Boston: Brill, 2018. p. 144-165. 
DUVE, Thomas. El concilio como instancia de autorización: La autorización sacerdotal de mestizos ante el Tercer Concilio Limense (1582/83) y la comunicación sobre Derecho durante la monarquía española. Revista de Historia del Derecho, n. 40, p. 01-29, 2010. Disponível em: http://www.scielo.org.ar/pdf/rhd/n40/n40a04.pdf.

DUVE, Thomas. Katholisches Kirchenrecht und Moraltheologie im 16. Jahrhundert: Eine globale normative Ordnung im Schatten schwacher Staatlichkeit. In: KADELBACH, Stefan, GÜNTHER, Kaus (Eds.). Recht ohne Staat?: Zur Normativität nichtstaatlicher Rechtsetzung. Frankfurt am Main; New York (NY): Campus Verlag, 2011. p. 147-174.

DUVE, Thomas. Von der Europäischen Rechtsgeschichte zu einer Rechtsgeschichte Europas in globalhistorischer Perspektive. Rechtsgeschichte - Legal History, [S. 1.], n. 20, p. 18-71, 2012. DOI: https://doi.org/10.12946/rg20/018-071.

DUVE, Thomas. Salamanca in Amerika. Zeitschrift der Savigny-Stiftung für

Rechtsgeschichte: Germanistische Abteilung, [S. 1.], v. 132, n. 1, p. 116-151, 2015. DOI: https://doi.org/10.7767/zrgga-2015-0108.

DUVE, Thomas. Global Legal History: a methodological approach. v. 1. [S. 1.]: Oxford University Press, 2017a. E-book. DOI:

https://doi.org/10.1093/oxfordhb/9780199935352.013.25.

DUVE, Thomas. Was ist $>$ Multinormativität $<$ ? - Einführende Bemerkungen. Rechtsgeschichte - Legal History, [S. 1.], n. 25, p. 088-101, 2017b. DOI: https://doi.org/10.12946/rg25/088-101.

DUVE, Thomas. Global Legal History: Setting Europe in Perspective. In: PIHLAJAMÄKI, Heikki et al. (Eds.). The Oxford Handbook of European Legal History. Oxford: Oxford University Press, 2018a. p. 01-29. DOI:

https://doi.org/10.1093/oxfordhb/9780198785521.013.5.

DUVE, Thomas. Indigenous Rights in Latin America. In: DUBBER, Markus; TOMLINS, Christopher (Eds.). The Oxford Handbook of Legal History. Oxford: Oxford University Press, 2018b. p. 817-837. DOI: https://doi.org/10.1093/oxfordhb/9780198794356.013.42.

DUVE, Thomas. Legal traditions: A dialogue between comparative law and comparative legal history. Comparative Legal History, [S. 1.], v. 6, n. 1, p. 15-33, 2018c. DOI:

https://doi.org/10.1080/2049677X.2018.1469271.

DUVE, Thomas. The School of Salamanca: A case of global knowledge production?. In: DUVE, Thomas et al. (Eds.). The School of Salamanca: A case of global knowledge production?. Leiden: Brill, 2020 (no prelo).

DUVE, Thomas; EGÍO GARCIA, José Luis; BIRR, Christiane (Eds.). The School of Salamanca: A case of global knowledge production?. Leiden: Brill, 2020 (no prelo).

ERDÖ, Péter. Geschichte der Wissenschaft vom kanonischen Recht: Eine Einführung. Berlin: Lit Verlag, 2006. 
ERLER, Adalbert. Populäre Rechtsliteratur. In: CORDES, Albrecht et al. (Eds.).

Handwörterbuch zur deutschen Rechtsgeschichte. v. 3. Berlin: Erich Schmidt Verlag, 1984. p. $1825-1828$.

FERNANDEZ, Angela. Legal History as the History of Legal Texts. In: DUBBER, Markus; TOMLINS, Christopher (Eds.). The Oxford Handbook of Legal History. Oxford: Oxford University Press, 2018. p. 243-290.

FERNANDEZ, Angela; DUBBER, Markus (Eds.). Law Books in Action: Essays on the Anglo-American Legal Treatise. Oxford, Portland (OR): Hart Publishing, 2012.

FIREY, Abigail. Mutating Monsters: Approaches to "Living Texts" of the Carolingian Era. In: Digital Proceedings of the Lawrence J. Schoenberg Symposium on Manuscript Studies in the Digital Age: Lex scripta: The Manuscript as Witness to the History of Law, [s. 1.], v. 2, n. 1, p. 1-14, 2010. Disponível em: https://repository.upenn.edu/ljsproceedings/vol2/iss1/1.

FOLGADO, Avelino. Los tratados De legibus y De iustitia et iure en los autores españoles del siglo XVI y primera mitad del XVII. La Ciudad de Dios, vol. 72, n. 3, p. 275-302, 1959.

FUCHSIUS, Bernhard. Institutiones theologiae christianae moralis. vol. 1. Augsburg: [s.n.], 1848.

GARCÍA-GALLO, Alfonso. El cedulario de Encinas. In: GARCÍA-GALLO, Alfonso (Ed.). Los orígenes españoles de las instituciones americanas: Estudios de derecho indiano. Madrid: Real Academia de Jurisprudencia y Legislación, 1992. p. 131-255.

GARRIGA ACOSTA, Carlos Antonio. Sobre el gobierno de la justicia en Indias (Siglos XVIXVII). Revista de Historia del Derecho, vol. 34, p. 67-160, 2006. Disponível em: $<\mathrm{http}: / /$ dialnet.unirioja.es/servlet/articulo?codigo $=2388772>$.

GROSSI, Paolo. A History of European Law. Malden (MA): Wiley-Blackwell, 2010.

HERZOG, Tamar. Frontiers of Possession: Spain and Portugal in Europe and the Americas. Cambridge (MA), London: Harvard University Press, 2015.

HERZOG, Tamar. A Short History of European Law: The Last Two and a Half Millennia. Cambridge (MA): Harvard University Press, 2018.

HESPANHA, António Manuel. Form and content in early modern legal books. Bridging the gap between material bibliography and the history of legal thought. Rechtsgeschichte, vol. 12, p. 12-50, 2008. DOI: https://doi.org/10.12946/rg12/012-050

HESPANHA, António Manuel. A cultura jurídica europeia: Síntese de um milénio. Coimbra: Almedina, 2012.

HESPANHA, António Manuel. Como os juristas viam o mundo, 1550-1750: Direitos, estados, coisas, contratos, ações e crimes. Lisboa: CreateSpace Independent Publishing Platform, 2015. 
HESPANHA, António Manuel. O 'direito de Índias' no contexto da historiografia das colonizações ibéricas. In: CONGRESO DEL INSTITUTO INTERNACIONAL DE HISTORIA DEL DERECHO INDIANO, 19., 2016, Berlin. Actas... Editadas por Thomas Duve. Madrid: Dickinson, 2017. p. 43-83.

HESPANHA, António Manuel. Southern Europe (Italy, Iberian Peninsula, France). In: PIHLAJAMÄKI, Heikki et al. (Eds.). The Oxford Handbook of European Legal History. Oxford: Oxford University Press, 2018. p. 332-356.

HESPANHA, António Manuel. Filhos da terra: Identidades mestiças nos confins da expansão portuguesa. Lisboa: Tinta da China, 2019.

HOLTHÖFER, Ernst. Die Literatur zum gemeinen und partikularen Recht in Italien, Frankreich, Spanien und Portugal. In: COING, Helmut (Hgg.). Handbuch der Quellen und Literatur der neueren europäischen Privatrechtsgeschichte: Neuere Zeit (1500-1800): Das Zeitalter des gemeinen Rechts. B. II. T. 1. München: C. H. Beck, 1977. p. 103-499.

HOOCK, Jochen; JEANNIN, Pierre (Eds.). Ars Mercatoria: Handbücher und Traktate für den Gebrauch des Kaufmanns. Manuels et traités á 1'usage des marchands 1420-1820. v. 1 (14701600). Paderborn: Schöningh, 1991.

JANSEN, Nils. Kommentare in Recht und Religion. In: KÄSTLE, David; JANSEN, Nils (Hgg.). Kommentare in Recht und Religion. Tübingen: Mohr Siebeck, 2014. p. 01-14.

KÄSTLE-LAMPARTER, David. Welt der Kommentare. Struktur, Funktion und Stellenwert juristischer Kommentare in Geschichte und Gegenwart. Tübingen: Mohr Siebeck, 2016.

KRASNER, Stephen D. Structural causes and regime consequences: regimes as intervening variables. In: KRASNER, Stephen D. (Ed.). International Regimes. Ithaka (NY): Cornell University Press, 1983. p. 01-21.

LIST, Martin. Regimetheorie. In: BENZ, Arthur et al. (Hgg.). Handbuch Governance. Theoretische Grundlagen und empirische Anwendungsfelder. Wiesbaden: VS Verlag für Sozialwissenschaften, 2007. p. 226-239.

MAHONEY, John. The Making of Moral Theology: A Study of the Roman Catholic Tradition. Reprint ed. Oxford; New York (NY): Clarendon Paperbacks, 1989.

MARCOCCI, Giuseppe. Conscience and Empire: Politics and Moral Theology in the Early Modern Portuguese World. Journal of Early Modern History, vol. 18, n. 5, p. 473-494, 2014.

MÖLLERS, Christoph. Die Möglichkeit der Normen. Über eine Praxis jenseits von Moralität und Kausalität. Berlin: Suhrkamp, 2015.

MOUTIN, Osvaldo R. „Sepamos, Señores, en que ley vivimos y si emos de tener por nuestra regla al Consejo de Indias“" - Salamanca in the Philppine Islands. In: DUVE, Thomas et al. (Eds.). The School of Salamanca: A case of global knowledge production?. Leiden: Brill, 2020 (no prelo). 
MÜLLER-WILLE, Staffan; REINHARDT, Carsten; SOMMER, Marianne. Wissenschaftsgeschichte und Wissensgeschichte. In: MÜLLER-WILLE, Staffan et al. (Hgg.). Handbuch Wissensgeschichte. Stuttgart: J. B. Metzler, 2017. p. 02-18.

MÜNSTERSCHE MITTELALTER-SCHRIFTEN, 65, 1989. Pragmatische Schriftlichkeit im Mittelalter. Erscheinungsformen und Entwicklungsstufen. Herausgegeben von Hagen Keller, Klaus Grumüller und Nikolaus Staubach. München: Fink, 1992. 356 p.

MUTHER, Theodor. Zur Geschichte der mittelalterlichen Rechtsliteratur für „pauperes“ und „minores“, reprinted version of 1869. In: MUTHER, Theodor (Hgg.). Zur Geschichte der Rechtswissenschaft und der Universitäten in Deutschland. Jena 1876; Amsterdam, 1961. p. 158-200. (Collected essays)

NEUHEUSER, Hanns Peter. Kanonistik, Pragmatik, Archivistik, Historik. Vom kanonistischen Alltagsdokument zur kirchenrechtsgeschichtlichen Quelle. In: NEUHEUSER, Hanns Peter (Hgg.). Pragmatische Quellen der kirchlichen Rechtsgeschichte. Köln; Weimar; Wien: Böhlau, 2011.p. 01-17.

NEUMANN, Birigt. Kulturelles Wissen. In: NÜNNING, Ansgar (Hgg.). Metzler Lexikon Literatur- und Kulturtheorie: Ansätze-Personen-Grundbegriffe. 5. ed. Stuttgart; Weimar: Springer, 2013.

O'BANION, Patrick J. The Sacrament of Penance and Religious Life in Golden Age Spain. University Park (PA): Pennsylvania State University Press, 2012.

OWENSBY, Brian P.; ROSS, Richard J. (Eds.). Justice in a New World: Negotiating Legal Intelligibility in British, Iberian, and Indigenous America. New York (NY): New York University Press, 2018.

PIHLAJAMÄKI, Heikki; DUBBER, Markus; GODFREY, Mark (Eds.). The Oxford Handbook of European Legal History. Oxford: Oxford University Press, 2018.

PINCKAERS, Servais. Les sources de la morale chrétienne. Paris: Univ. Fribourg Suisse, 2004.

PRODI, Paolo. Una storia della giustizia: Dal pluralismo dei fori al moderno dualismo tra coscienza e diritto. Bologna: Società Editrice il Mulino, 2000.

RANIERI, Filippo. Juristische Literatur aus dem Ancien Regime und historische Literatursoziologie. Einige methodologische Vorüberlegungen. In: BERGFELD, C. et al. (Hgg.). Aspekte europäischer Rechtsgeschichte. Festgabe für Helmut Coing zum 70. Geburtstag. Frankfurt am Main: Vittorio Klostermann, 1982. p. 292-322.

RAPPAPORT, Joanne; CUMMINS, Tom (Eds.). Beyond the lettered city: Indigenous literacies in the Andes. Raleigh; Durham (NC): Duke University Press, 2011.

RENN, Jürgen. The Globalization of Knowledge in History and its Normative Challenges.

Rechtsgeschichte - Legal History, vol. 22, p. 52-60, 2014. DOI:

https://doi.org/10.12946/rg22/052-060 
RENN, Jürgen. From the History of Science to the History of Knowledge - and Back. Centaurus, vol. 57, n. 1, 2015, p. 37-53. DOI: <https://doi.org/10.1111/1600-0498.12075>.

RENN, Jürgen; HYMAN, Malcolm H. The Globalization of Knowledge in History: An Introduction. in: RENN, Jürgen (Ed.). The Globalization of Knowledge in History. Berlin: Edition Open Access, 2012. p. 15-44. Disponível em: $<$ http://www.edition-open-access.de/media/studies/1/5/Studies1ch1.pdf $>$.

SÁNCHEZ BELLA, Ismael. Estudio preliminar. In: SÁNCHEZ BELLA, Ismael (Ed.). Recopilación de las Indias, por Antonio de León Pinelo. 3 vol. México: Miguel Ángel Porrúa, 1992. p. 17-64.

SARANYANA, Josep Ignasi et al. (Eds.). Teología en América Latina: Desde los orígenes a la Guerra de Sucesión (1493-1715). vol. 1. Madrid: Iberoamericana, 1999.

SCHMIDT-WIEGAND, Ruth. Populärjurisprudenz zwischen Artesliteratur und Richterlichem Clagspiegel. In: WICH-REIF, Claudia (Hgg.). Strukturen und Funktionen in Gegenwart und Geschichte. Festschrift für Franz Simmler zum 65. Geburtstag. Berlin: Weidler Buchverlag, 2007. p. 537-554.

SCHRÖDER, Jan. Recht als Wissenschaft. Geschichte der juristischen Methodenlehre in der Neuzeit (1500-1933). 2. Auflage. München: Verlag C.H.Beck, 2012.

SCHULTE, Johann Friedrich von. Die Geschichte der Quellen und Literatur des Canonischen Rechts von Gratian bis auf die Gegenwart. B. II. Stuttgart: Verlag von Ferdinand Enke, 1877.

SCHUMANN, Eva. Wissensvermittlung leicht gemacht. Die Vermittlung gelehrten Rechts an ungelehrte Rechtspraktiker am Beispiel der volkssprachigen Teufelsprozesse. In: REICH, Björn et al. (Hgg.). Wissen, maßgeschneidert. Experten und Expertenkulturen im Europa der Vormoderne. München: Oldenbourg, 2012. p. 182-213.

SCHUMANN, Eva. Rechts- und Sprachtransfer am Beispiel der volkssprachigen Praktikerliteratur. In: DEUTSCH, Andreas (Hgg.). Historische Rechtssprache des Deutschen. Heidelberg: Universitätsverlag Winter, 2013. p. 123-174.

SECKEL, Emil. Beiträge zur Geschichte beider Rechte im Mittelalter: Zur Geschichte der populären Literatur des römisch-canonischen Rechts. B. I. Tübingen: Verlag der Laupp'schen Buchhandlung, 1898.

SIMPSON, Alfred William Brian. The Rise and Fall of the Legal Treatise: Legal Principles and the Forms of Legal Literature. University of Chicago Law Review, vol. 48, n. 3, p. 632679, 1981. Disponível em: <https://chicagounbound.uchicago.edu/uclrev/vol48/iss3/4>.

SÖLLNER, Alfred. Die Literatur zum gemeinen und partikularen Recht in Deutschland, Österreich, den Niederlanden und der Schweiz. In: COING, Helmut (Hgg.). Handbuch der Quellen und Literatur der neueren europäischen Privatrechtsgeschichte. Neuere Zeit (15001800). Das Zeitalter des gemeinen Rechts. B. II. T. 1. München: C. H. Beck, 1977. p. 501614. 
STINTZING, Johann August Roderich von. Geschichte der populären Literatur des römischkanonischen Rechts in Deutschland am Ende des fünfzehnten und im Anfang des sechszehnten Jahrhunderts. Leipzig: S. Hirzel, 1867.

TAU ANZOÁTEGUI, Víctor. Casuismo y Sistema: Indagación histórica sobre el espíritu del Derecho Indiano. Buenos Aires: Instituto de Investigaciones de Historia del Derecho, 1992.

THEINER, Johann. Die Entwicklung der Moraltheologie zur eigenständigen Disziplin. Regensburg: Friedrich Pustet, 1970.

TROJE, Hans Erich. Die Literatur des gemeinen Rechts unter dem Einfluß des Humanismus. In: COING, Helmut (Hgg.). Handbuch der Quellen und Literatur der neueren europäischen Privatrechtsgeschichte. Neuere Zeit (1500-1800). Das Zeitalter des gemeinen Rechts. B. II. T. 1. München: C. H. Beck, 1977. p. 615-795.

VALLERIANI, Matteo. The Epistemology of Practical Knowledge. In: VALLERIANI, Matteo (Ed.). The Structures of Practical Knowledge. Dordrecht: Springer, 2017a. p. 01-19.

VALLERIANI, Matteo (Ed.). The Structures of Practical Knowledge. Dordrecht: Springer, $2017 \mathrm{~b}$.

VAN HOVE, Alphonse. Prolegomena (Commentarium Lovaniense in Codicem Iuris Canonici). Mecheln; Rome: Dessain, 1945.

VEREECKE, Louis. Storia della teologia morale moderna. v. 2. Roma: [s.n.], 1973.

VESTING, Thomas. Legal Theory. München: C. H. Beck, 2018.

VIDAL, Marciano. Historia de la teología moral: La moral en la edad moderna (s. XV-XVI). T. 4 (Humanismo y Reforma). v. 1. Madrid: Perpetuo Socorro, 2012.

WEHLING, Peter. Wissensregime. In: SCHÜTZEICHEL, Rainer (Hgg.). Handbuch Wissenssoziologie und Wissensforschung. Konstanz: UVK, 2007. p. 704-712

WHITE, James Boyd. Legal Knowledge. Harvard Law Review, vol. 115, n. 5, 2002, p. 13961431. Disponível em: <https://www.jstor.org/stable/1342550>.

WIEACKER, Franz. A History of Private Law in Europe. Oxford: Clarendon Press, 1969.

WITTMANN, Piotr. „Der da sein Practic auß Teutschen Tractaten will lernen“: Rechtspraktiker in deutschsprachiger Praktikerliteratur des 16. Jahrhunderts. Frankfurt am Main: PL Academic Research, 2015.

WOHLMUTH, Josef (Ed.). Dekrete der ökumenischen Konzilien. Konzilien der Neuzeit. 3 Bände. Paderborn: Ferdinand Schöningh, 2001.

ZITTEL, Claus. Wissenskulturen, Wissensgeschichte und historische Epistemologie. In: SANDKÜHLER, Hans Jörg (Hgg.). Wissen. Wissenskulturen und die Kontextualität des Wissens. Frankfurt am Main: Peter Lang, 2014. p. 91-109. 
DADOS DA PUBLICAÇÃO

Categoria: artigo de autor convidado.

Recebido em: 10/04/2020.

Aceito em: 20/04/2020. 
